\title{
Comparação cruzada entre pesquisas laboratoriais e de campo em conforto térmico em espaços abertos urbanos
}

Cross comparison between laboratorial research and field research in thermal comfort in outdoor urban spaces

\section{Leonardo Marques Monteiro Márcia Peinado Alucci}

\section{Resumo}

$\mathbf{E}$

ste artigo apresenta uma comparação cruzada entre pesquisas laboratoriais e de campo em conforto térmico em espaços abertos urbanos. O objetivo da pesquisa é verificar comparativamente os resultados de bases empíricas laboratoriais e de campo, estabelecidas na cidade de São Paulo. Para tanto, consideram-se modelos preditivos desenvolvidos, adaptados ou utilizados em pesquisas de conforto térmico em espaços abertos. Ao mesmo tempo, verificam-se comparativamente os referidos modelos, com indicação de uso daqueles que apresentaram resultados mais significativos para diferentes aplicações. O método utilizado é empírico-indutivo, por meio de coleta de dados laboratoriais e levantamentos em campo (variáveis microclimáticas, pessoais e subjetivas), apoiado por método teórico-dedutivo, por meio de simulações computacionais (29 índices referentes a 20 modelos preditivos). Verificou-se que os resultados das respostas de percepção de sensação térmica apresentam-se menos predizíveis no Bairro da Luz (levantamento de campo) do que na Cidade Universitária (coleta laboratorial). Com relação aos índices, o índice de carga térmica, a temperatura equivalente percebida e a nova temperatura efetiva corrigida foram os que apresentaram resultados mais significativos, sendo indicada a aplicação para cada um deles.

Palavras-chave: Conforto térmico. Espaços abertos. Modelos preditivos.

Leonardo Marques Monteiro Faculdade de Arquitetura e Urbanismo Universidade de São Paulo Cidade Universitária, Rua do Lago,

São Paulo - SP - Brasil CEP 05508.080 Tel.: (11) 3091-4538

E-mail: leo4mm@gmail.com

\begin{abstract}
Márcia Peinado Alucci Faculdade de Arquitetura e Urbanismo Universidade de São Paulo Tel.: (11) 3091-4538 E-mail: marciaalu@usp.br
\end{abstract}

Recebido em 21/06/10 Aceito em 01/08/10

\section{Abstract}

This paper presents a cross comparison between laboratorial and field research in thermal comfort for outdoor urban areas. The aim of this research study is to make a comparative analysis of the data from of empirical laboratory and field databases, collected in the city of São Paulo. In order to do so, predictive models developed, adapted or used in outdoor thermal comfort studies were considered. At the same time, these models also underwent a comparative analysis, leading to the indication of those with more significant results for different applications. The method adopted is empirical, through laboratory- and field data collection (microclimatic, personal and subjective variables), supported by computer simulations (29 indices related to 20 predictive models). The results of thermal sensation perception in the Bairro da Luz (field study) showed to be less predictable than those obtained in Cidade Universitária (laboratory study). With regards to the indices, the heat load, the temperature of equivalent perception, and the new corrected effective temperature presented the most significant results, and their application is suggested.

Keywords: Thermal comfort. Outdoors. Predictive models. 


\section{Introdução}

As pesquisas de conforto térmico têm por característica histórica estabelecer sua base empírica principalmente em estudos laboratoriais ou em levantamentos de campo. Os estudos de conforto térmico em espaços fechados originalmente deram primazia ao caráter laboratorial, culminando no modelo de Fanger (1972), baseado no voto médio estimado e na porcentagem de pessoas insatisfeitas, que hoje é indicado pelas principais normas internacionais (ISO, 2005; ASHRAE, 2004). Por outro lado, na atualidade, verificam-se também estudos significativos baseados em levantamentos de campo DEAR; BRAGER; COOPER, 1997), chegando à indicação por norma internacional (ASHRAE, 2004) da utilização de referida modelagem para o caso de espaços naturalmente ventilados. Já uma revisão bibliográfica dos estudos de conforto térmico em espaços abertos (MONTEIRO; ALUCCI, 2005) parece indicar uma característica diferenciada. Devido ao fato de modelos para esse tipo de espaços terem se desenvolvido mais acentuadamente apenas no final do século passado, grande parte dos estudos se utiliza de modelos, ou adaptações de modelos, desenvolvidos para espaços fechados. Ao mesmo tempo, o desenvolvimento de modelos específicos indica a existência concomitante de pesquisas baseadas em bases empíricas laboratoriais e de levantamentos de campo. O parágrafo seguinte traz uma breve revisão dos modelos, apresentados pelos autores recém-citados. Assim, o objetivo desta pesquisa é verificar comparativamente, considerando modelos preditivos desenvolvidos, adaptados ou utilizados em pesquisas de conforto térmico em espaços abertos, os resultados de bases empíricas laboratoriais e de campo. Ao mesmo tempo, verificam-se comparativamente os referidos modelos, com indicação de uso daqueles que apresentaram resultados mais significativos, considerando diferentes aplicações.

As primeiras pesquisas de conforto térmico têm caráter iminentemente laboratorial, focando-se, na maioria, em espaços fechados, mas tendo-se posteriormente sido adaptadas para, ou utilizadas em, espaços abertos. Houghten e Yaglou (1923), a partir de estudos em laboratório da ASHVE, propõem a temperatura efetiva (ET), determinada por meio da combinação da temperatura de bulbo seco e de bulbo úmido e da velocidade do vento. Vernon e Warner (1932) propõem a nova temperatura efetiva (ET*), mediante a substituição da temperatura de bulbo seco pela temperatura de globo, para consideração dos efeitos da radiação. Esse índice foi adotado pela ASHRAE (1967), tendo sido posteriormente adotada a temperatura operativa, em vez da temperatura de globo, com a nomenclatura de nova temperatura efetiva corrigida (CET*). Siple e Passel (1945) desenvolvem a temperatura resfriada pelo vento (WCT) a partir dos dados obtidos com experiências laboratoriais em espaços abertos na Antártida. Belding e Hatch (1955) propõem o índice de estresse térmico por calor (HSI) para espaços externos, através de modelo de balanço térmico. Yaglou e Minard (1957) propõe a temperatura de globo e de bulbo úmido (WBGT), considerando situações internas e externas, sem e com radiação solar direta. Gagge, Stolwijk e Hardy (1967) propõe uma nova determinação para a temperatura efetiva padrão (SET*), podendo ser definida como a temperatura equivalente à temperatura do ar na qual, em um ambiente de referência, o indivíduo apresenta a mesma temperatura da pele e a mesma fração de pele coberta por suor regulatório que no ambiente em questão. Givoni (1969) propõe o índice de estresse térmico (ITS), baseado em balanço térmico, e, para considerar as trocas por radiação em ondas longas, o autor sugere a utilização da temperatura de globo em vez da temperatura do ar no cálculo das trocas convectivas. Masterton e Richardson (1979) propõem o Humidex (HU), índice que fornece uma temperatura equivalente em função dos valores da temperatura e da umidade relativa do ar. Jendrizky et al. (1979) propõem o Modelo Climático de Michel, baseado em adaptação do modelo proposto por Fanger (1972), através de um modelo de radiação que computa os fluxos de radiação de ondas longa e curta, considerando-os no valor de temperatura radiante média. Vogt et al. (1981) propõem o índice de taxa de suor requerida (Swreq), a partir do HSI e do ITS, tornando-se parte da norma ISO 7933 (1989). Domínguez et al. (1992) propõem critérios para a taxa de suor requerida com base no tipo de uso dos espaços. Brown e Gillespie (1995) propõem uma fórmula de conforto específica para ambientes externos. Aroztegui (1995) propõe a temperatura neutra exterior, a partir do trabalho de Humphreys (1975), baseado em levantamentos de campo. Este propõe a temperatura neutra, definida como a temperatura ambiente considerada termicamente neutra pela população. Aroztegui (1995) incorpora variáveis relativas à radiação solar e à velocidade do vento, baseando-se no ITS. Blazejczyk (2002) propõe o modelo de balanço térmico Menex, considerando uma série de índices de caráter laboratorial: carga térmica (HL), estímulo devido à intensidade de radiação (R'), esforço fisiológico (PhS), temperatura subjetiva (STI), índice de suor aparente (SP). Freitas (1997) apresenta o índice de 
capacidade de armazenamento (PSI) e a temperatura da pele que equilibra o balanço térmico (STE), também utilizando o modelo Menex. Höppe (1999) propõe o Modelo de Munich, baseando-se também na equação de balanço térmico, mas considerando o modelo de dois nós de Gagge (1986) e definindo a temperatura equivalente fisiológica (PET) de dada situação como a temperatura equivalente à temperatura do ar na qual, em uma situação típica interna, o balanço térmico do corpo humano é mantido, com temperaturas do centro do corpo e da pele iguais às da situação em questão. Givoni e Noguchi (2000) relatam pesquisa experimental de conforto térmico em espaços abertos, envolvendo aquisição de respostas de sensação térmica (TS) e sensação global de conforto em caráter laboratorial, através de pesquisa desenvolvida em um parque da cidade de Yokohama, no Japão. Bluestein e Osczevski (2002) realizaram trabalho de pesquisa empírica para reformulação das equações para determinar a nova temperatura resfriada pelo vento (NWCTI). Os ensaios para a determinação do novo índice basearam-se na modelagem física do rosto do indivíduo exposto ao vento. Nikolopoulou (2004) apresenta o voto real de sensação (ASV), em que, para cada uma das cidades europeias onde foram realizados levantamentos de campo, propôs-se uma equação linear simples, para predição de conforto baseado em dados de estação meteorológica, propondo-se ainda equação única representativa do continente. Monteiro (2008) propõe a temperatura equivalente percebida (TEP) com base em levantamentos laboratoriais na cidade de São Paulo, podendo ser definida como uma escala de sensação térmica que apresenta valores numericamente iguais aos da temperatura do ar de um ambiente de referência em que se verifica o mesmo valor médio de percepção de sensação térmica que no ambiente em questão.

Para melhor compreensão do panorama dessas pesquisas, assim como posterior discussão dos resultados da presente pesquisa, apresenta-se uma classificação dos modelos em questão, considerando-se conceitos modelares e modais. Consideram-se, ainda, seus respectivos índices, segundo o critério de interpretação por eles apresentado. A Tabela 1 apresenta a classificação proposta por Monteiro (2008).

\begin{tabular}{|c|c|c|c|c|c|c|}
\hline $\begin{array}{l}\text { Objeto de } \\
\text { predição }\end{array}$ & \multicolumn{6}{|c|}{ Esforço fisiológico (estresse) } \\
\hline $\begin{array}{c}\text { Método } \\
\text { predominante }\end{array}$ & \multicolumn{3}{|c|}{ Indutivo (modelos empíricos) } & \multicolumn{3}{|c|}{ Dedutivo (modelos analíticos) } \\
\hline Modelos & \multicolumn{3}{|c|}{$\begin{array}{l}\text { WCT (WCTI), WBGT } \\
\text { Humidex (HU), HSI, ITS } \\
\text { NWCT (NWCTI, Ft) }\end{array}$} & \multicolumn{3}{|c|}{$\begin{array}{c}\text { Vogt (Swreq, w, S) } \\
\text { Sevilha (Swreq') } \\
\text { Menex (HL, PhS, R', SP) } \\
\end{array}$} \\
\hline $\begin{array}{l}\text { Principal critério } \\
\text { interpretativo }\end{array}$ & Analogia & \multicolumn{2}{|c|}{ Parâmetros fisiológicos } & Analogia & \multicolumn{2}{|c|}{ Parâmetros fisiológicos } \\
\hline Índices & $\begin{array}{l}\text { WBGT }^{(1)} \\
\text { HU }^{(1)} \\
\text { NWCTI }^{(2)}\end{array}$ & \multicolumn{2}{|c|}{$\begin{array}{l}\mathrm{WCTI}^{(2)}, \mathrm{Ft}^{(2)}, \\
\mathrm{HSI}^{(1)}, \mathrm{ITS}^{2}\end{array}$} & - & \multicolumn{2}{|c|}{$\begin{array}{c}\text { Swreq,w, } \text { S }^{(1)}, \\
\text { Swreq }_{(1)} \\
\text { HL, PhS, R' }{ }^{(1)}, \text { SP }^{(1)}\end{array}$} \\
\hline $\begin{array}{c}\text { Objeto de } \\
\text { predição }\end{array}$ & \multicolumn{6}{|c|}{ Sensação térmica (conforto) } \\
\hline $\begin{array}{c}\text { Método } \\
\text { predominante }\end{array}$ & \multicolumn{3}{|c|}{ Indutivo (modelos empíricos) } & \multicolumn{3}{|c|}{ Dedutivo (modelos analíticos) } \\
\hline Modelos & \multicolumn{3}{|c|}{$\begin{array}{l}\text { ET }^{*}, \text { CET}^{*}, \text { OT, EOT* } \\
\text { Tne, TS, ASV }\end{array}$} & \multicolumn{3}{|c|}{$\begin{array}{l}\text { Gagge et al. (SET*), KMM (PMV) } \\
\text { COMFA (S'), Menex (STI, ECI) } \\
\text { De Freitas (PSI; STE), MEMI (PET) }\end{array}$} \\
\hline \multirow{2}{*}{$\begin{array}{l}\text { Principal critério } \\
\text { interpretativo }\end{array}$} & \multirow{2}{*}{ Analogia } & \multicolumn{2}{|c|}{ Parâmetros fisiológicos } & \multirow{2}{*}{ Analogia } & \multicolumn{2}{|c|}{ Parâmetros fisiológicos } \\
\hline & & Fisiológicos & Qualitativos & & Fisiológicos & Qualitativos \\
\hline Índices & $\begin{array}{c}\text { ET* }^{*} \\
\text { CET }^{*} \\
\text { OT, EOT* }\end{array}$ & - & $\begin{array}{l}\text { Tne, TS } \\
\text { ASV, } \\
\text { TEP }\end{array}$ & $\begin{array}{c}\text { SET* } \\
\text { STI, PET }\end{array}$ & $\begin{array}{l}\text { S', ECI } \\
\text { PSI, STE }\end{array}$ & $\begin{array}{l}\text { PMV } \\
\text { PPD }\end{array}$ \\
\hline
\end{tabular}

(1) Índices que consideram apenas exposição a situações térmicas quentes.

(2) Índices que consideram apenas exposição a situações térmicas frias.

Tabela 1 - Classificação de modelos e índices para predição de situações térmicas 
Os modelos são classificados segundo dois critérios: o objeto de predição e o método predominante de modelagem. Segundo o objeto de predição, tem-se a consideração ou do esforço fisiológico (cujos índices são comumente referidos como de estresse térmico), ou da sensação térmica (cujos índices são comumente considerados como de conforto térmico). Com relação ao método predominante de modelagem, tanto os modelos de esforço fisiológico quanto os modelos de sensação térmica podem ser subdivididos em modelos experimentais e modelos analíticos, segundo sejam, respectivamente, adotadas abordagens predominantemente indutivas ou dedutivas. Já os índices são classificados de acordo com seu principal critério interpretativo. Assim, os índices considerados baseiam-se predominantemente em um dos dois seguintes critérios: analogia ou parametrização. Quando a interpretação é realizada por meio de analogia, verifica-se, invariavelmente, a adoção de temperaturas equivalentes. Essas são temperaturas equivalentes de referência, no caso de modelos de esforço fisiológico, e temperaturas equivalentes de sensação térmica, no caso dos modelos que têm essa como objeto de predição. Em ambos os casos, é habitual o estabelecimento posterior de faixas interpretativas para os valores das temperaturas equivalentes. Nos casos em que não ocorre um processo analógico, observa-se o estabelecimento de um parâmetro específico, ou ainda da relação entre diversos parâmetros. No caso de índices de estresse térmico, os parâmetros são fisiológicos. Já com relação aos índices de conforto térmico, tem-se parametrização por meio de variáveis fisiológicas ou por meio de escalas arbitrárias de valores. Em ambos os casos verificase posterior correlação dos valores encontrados com respostas subjetivas. Dessa forma, ainda que nas duas situações tenha-se uma interpretação qualitativa subjetiva, convencionou-se a divisão dos índices parametrizados segundo a utilização de parâmetros ditos fisiológicos ou qualitativos. Esses foram assim chamados porque a escala de valores é arbitrada pelas respostas subjetivas, recaindo a ênfase no caráter qualitativo. Já aqueles foram assim chamados porque a escala de valores é determinada efetivamente pelo parâmetro ou relação de parâmetros fisiológicos. Por fim, ressalta-se que, conforme pode ser observado na tabela, determinados índices de modelos de esforço fisiológico consideram apenas exposições a situações térmicas de calor ou frio.

\section{Métodos}

Apresentam-se aqui os levantamentos de campo realizados com o objetivo de obtenção de dados empíricos para efetuar a verificação comparativa com as simulações computacionais dos modelos preditivos. Consideram-se inicialmente os levantamentos laboratoriais e então os levantamentos de campo. Em seguida, são apresentados os critérios, métodos e procedimentos de quantificação das variáveis ambientais (temperatura do ar, pressão parcial de vapor, velocidade do ar e temperatura radiante média), individuais (taxa metabólica e resistência térmica da roupa) e subjetivas (percepção de sensação e conforto térmico).

\section{Levantamentos laboratoriais}

Os levantamentos laboratoriais foram realizados em espaços abertos da Cidade Universitária, na cidade de São Paulo. Ressalta-se aqui o caráter laboratorial na medida em que as pessoas que respondem aos questionários são conduzidas aos locais e em que as condições de exposição (atividades, roupas e locais de permanência e exposição) sofrem controle. Realizaram-se os levantamentos em dias típicos de verão e de inverno.

Para a realização dos procedimentos, foram estabelecidas três bases visando à determinação das grandezas físicas: uma primeira a céu aberto, uma segunda sob copa de árvores e uma terceira sob cobertura têxtil tensionada. Uma base central, com sensores de velocidade e direção de vento a $10 \mathrm{~m}$ de altura, foi estabelecida para referenciar as variáveis ambientais, situando-se espacialmente entre as três bases citadas. No total, em cada dia, foram entrevistadas cerca de 150 pessoas, em cada uma das três bases, em seis horários diferentes. Esse procedimento foi realizado em dias representativos de verão e em dias representativos de inverno, totalizando 72 situações microclimáticas distintas, com a aplicação de 1.750 questionários. Os levantamentos foram realizados estabelecendo-se dois grupos de 75 pessoas. Realizaram-se os procedimentos com o primeiro grupo nos três primeiros horários, repetindo-se os procedimentos com o segundo grupo nos três horários seguintes. Cada grupo foi subdividido em três, cada um de 25 integrantes. Cada subgrupo dirigiu-se a uma base. Na primeira base, todas as pessoas receberam etiquetas identificadoras (A01-A25, B01-B25, C01-C25), responderam a um questionário para verificação de características gerais (sexo, idade, peso, altura) e aclimatação (locais onde já viveu e por quanto tempo), e foram fotografadas (em grupos de cinco) para posterior identificação da vestimenta. Após esses procedimentos iniciais, todos ficaram $20 \mathrm{~min}$ expostos às condições ambientes locais, para em seguida receberem um questionário de percepção e 
preferência de sensação térmica. Nesse questionário, perguntou-se também se alguma peça de roupa foi alterada desde o momento do registro fotográfico. Depois de respondidos, os questionários foram recolhidos, e cada grupo se dirigiu à próxima base, onde permaneceu por mais $30 \mathrm{~min}$, realizando-se o mesmo procedimento até ter passado pelas três bases. $\mathrm{O}$ segundo grupo de
75 pessoas passou então pelos mesmos procedimentos, mas a troca de bases foi realizada em sentido inverso ao do primeiro grupo. As Figuras 1, 2 e 3 apresentam respectivamente localização, ambientes e condições de exposição ao céu das três bases monitoradas na Cidade Universitária.

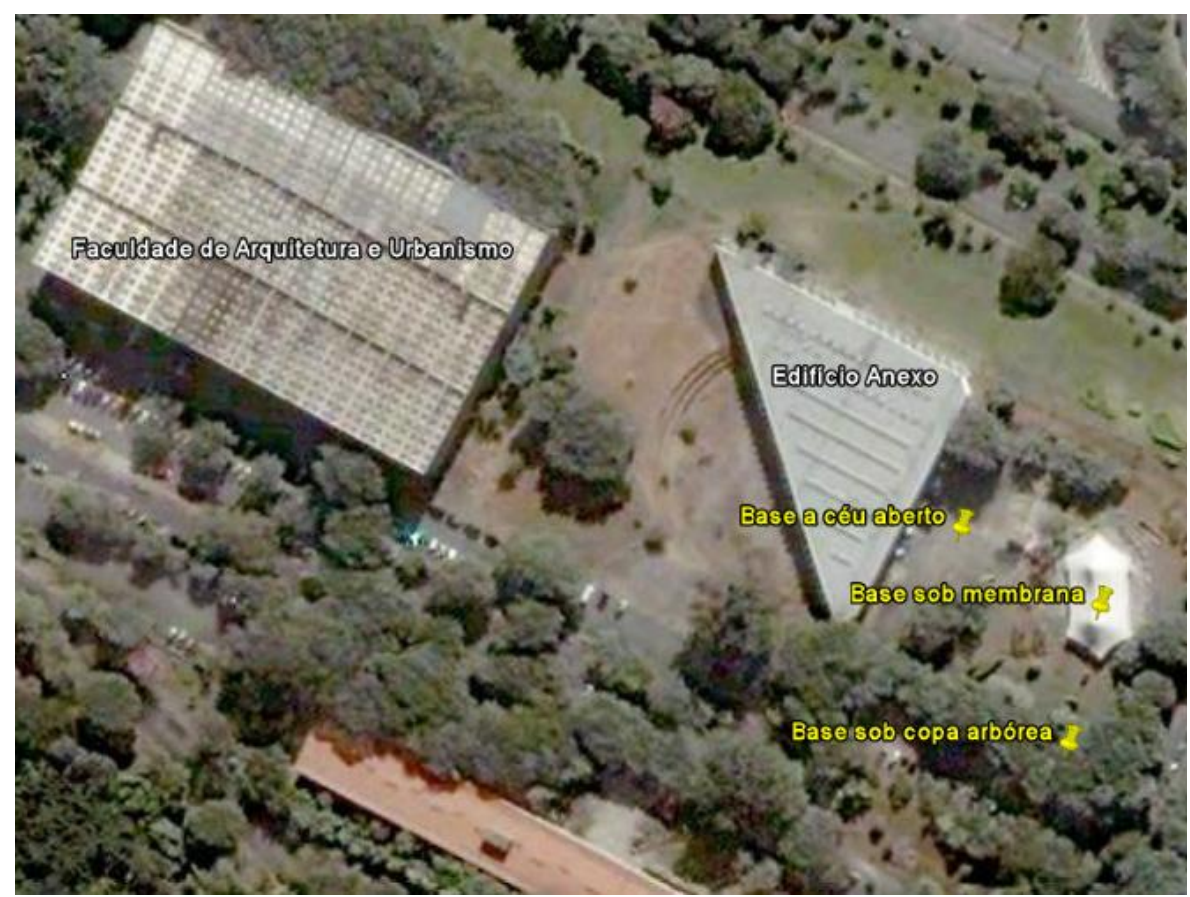

Figura 1 - Locais levantados empiricamente na Cidade Universitária
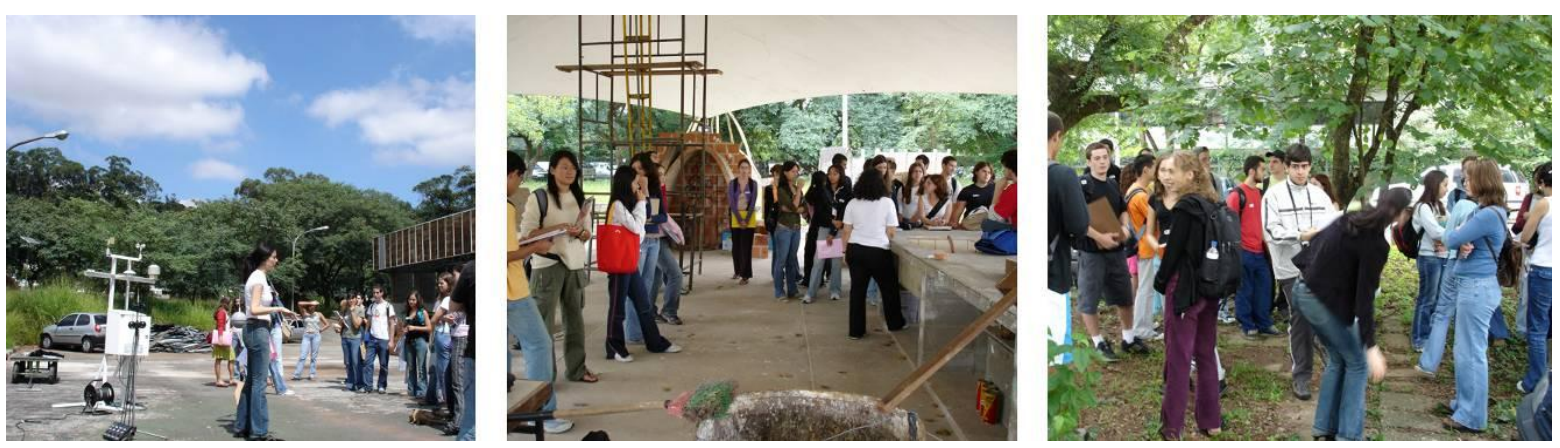

Figura 2 - Vista das bases levantadas empiricamente na Cidade Universitária
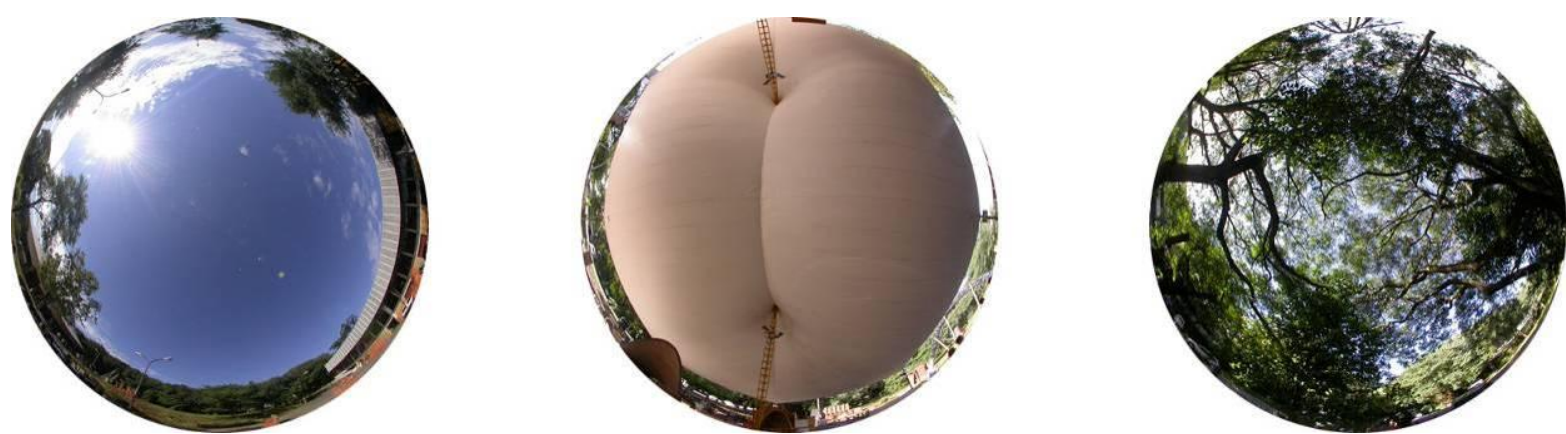

Figura 3 - Condições de exposição ao céu das bases na Cidade Universitária 


\section{Levantamentos de campo}

Nesta pesquisa, realizaram-se levantamentos de campo em situações urbanas reais, aplicando-se os questionários a usuários dos espaços em questão. A base empírica estabelecida abrange conjunto de dados de levantamentos realizados em dias de verão e de inverno no Bairro da Luz, em São Paulo, SP.

Considerando o bairro em questão, e devido à quantidade de equipamentos disponíveis, foram estabelecidas três bases para levantamentos simultâneos, sendo ao todo abarcados cinco locais distintos, apresentados na figura seguinte $\mathrm{e}$ selecionados com base nos critérios a serem explicitados. A eleição das bases se deu buscando a diversidade de configurações tipológicas. Buscou-se ainda a eleição de locais que se configurassem, simultaneamente, como de passagem e de permanência, ou seja, em que se pudesse identificar a realização das atividades comumente exercidas em espaços abertos urbanos. Dessa forma, os levantamentos de verão foram realizados em uma rua (Rua dos Andradas), em uma praça (Praça Sala São Paulo) e em um parque (Parque da Luz). Ressalta-se que o primeiro local é predominantemente de passagem, o terceiro é predominantemente de permanência, e o segundo apresenta as duas situações. Nos levantamentos de inverno, devido à menor quantidade de pessoas disponíveis para sua realização, somada às dificuldades encontradas para o gerenciamento simultâneo dos levantamentos nos diferentes locais, em especial devido à distância física entre o parque e os demais pontos e à periculosidade do percurso, optou-se pela seleção de locais mais próximos entre si, mas que mantivessem as características inicialmente estabelecidas. Dessa forma, buscaram-se a diversidade tipológica e a heterogeneidade de usos. Ao mesmo tempo, optouse por manter um mesmo ponto levantado no período de verão, para que comparações diretas pudessem ser realizadas, além de se estabelecer um denominador comum. Assim, manteve-se o ponto do parque (Parque da Luz), com uso predominante de permanência. Os demais pontos para realização dos levantamentos foram estabelecidos considerando-se uma rua e uma praça, apresentando assim características tipológicas e de uso distintas, sendo um local de passagem e de permanência (Praça da Luz, na entrada do Parque da Luz) (Figura 4) e um local de passagem (na entrada da Estação da Luz).

Em resumo, a Tabela 2 apresenta os locais levantados empiricamente, no verão e no inverno, e os usos predominantes.

As Figuras 5 a 8 apresentam os ambientes físicos e as condições de exposição ao céu de cada uma das bases levantadas no verão (Rua dos Andradas, Praça Sala São Paulo e Parque da Luz) e no inverno (Estação da Luz, Praça da Luz e Parque da Luz).

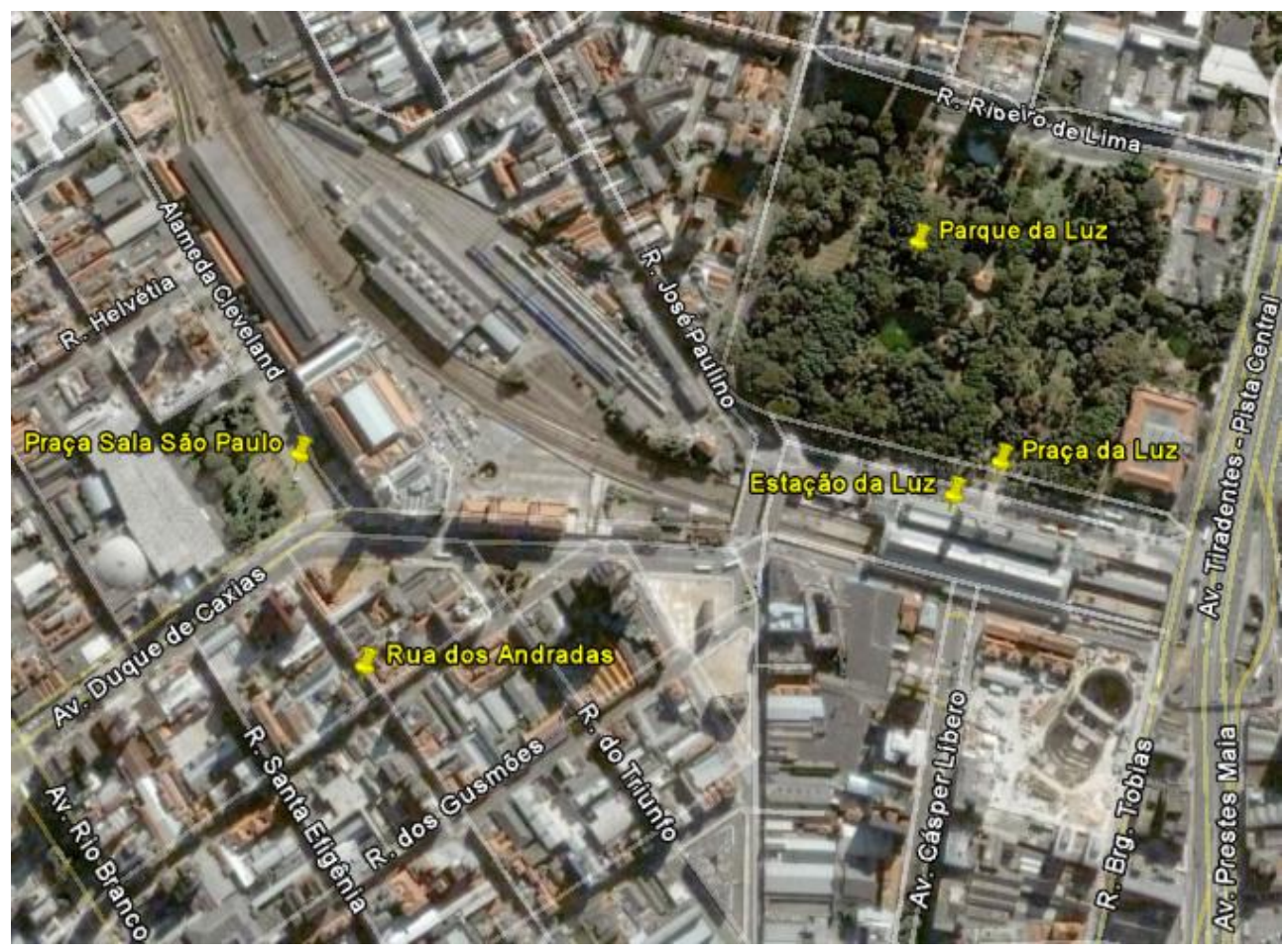

Figura 4 - Locais levantados empiricamente no Bairro da Luz 


\begin{tabular}{l|l|l|l}
\hline Tipologia & \multicolumn{1}{|c|}{ Uso predominante } & \multicolumn{1}{c}{ Verão } & \multicolumn{1}{c}{ Inverno } \\
\hline Rua & Passagem & Rua dos Andradas & Estação da Luz \\
\hline Praça & Passagem/Permanência & Praça Sala São Paulo & Praça da Luz \\
\hline Parque & Permanência & Parque da Luz & Parque da Luz \\
\hline
\end{tabular}

Tabela 2 - Locais levantados empiricamente
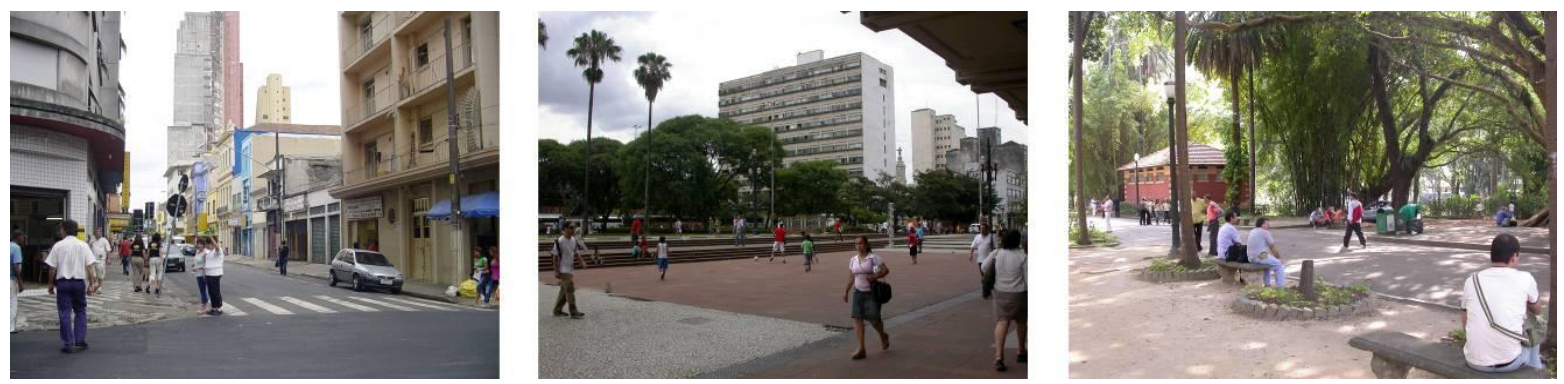

Figura 5 - Vista das bases levantadas empiricamente no Bairro da Luz no verão
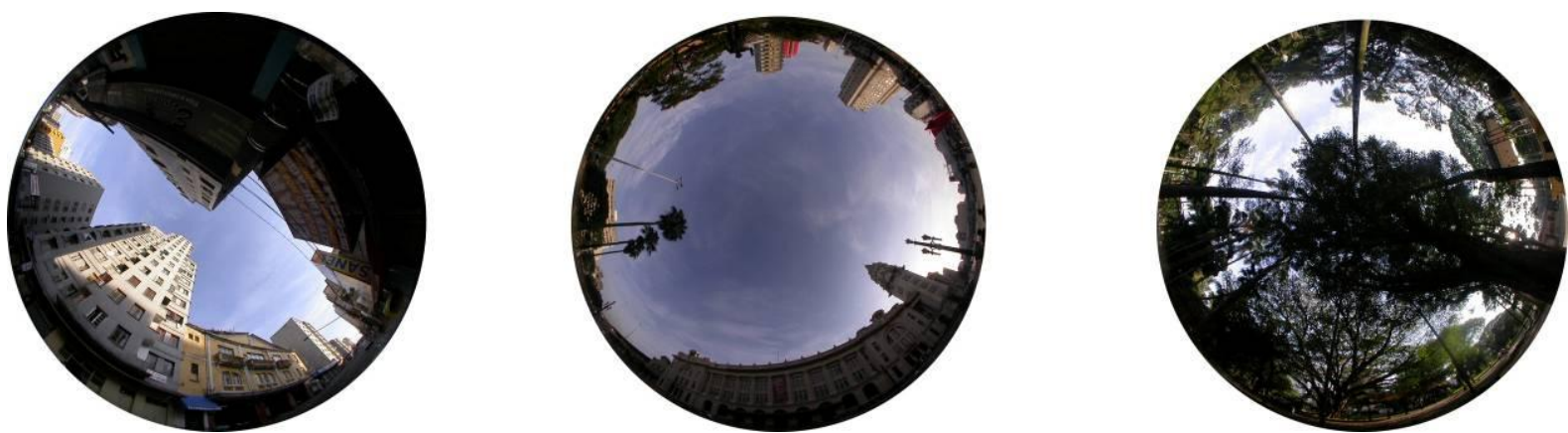

Figura 6 - Condições de exposição ao céu das bases no Bairro da Luz no verão
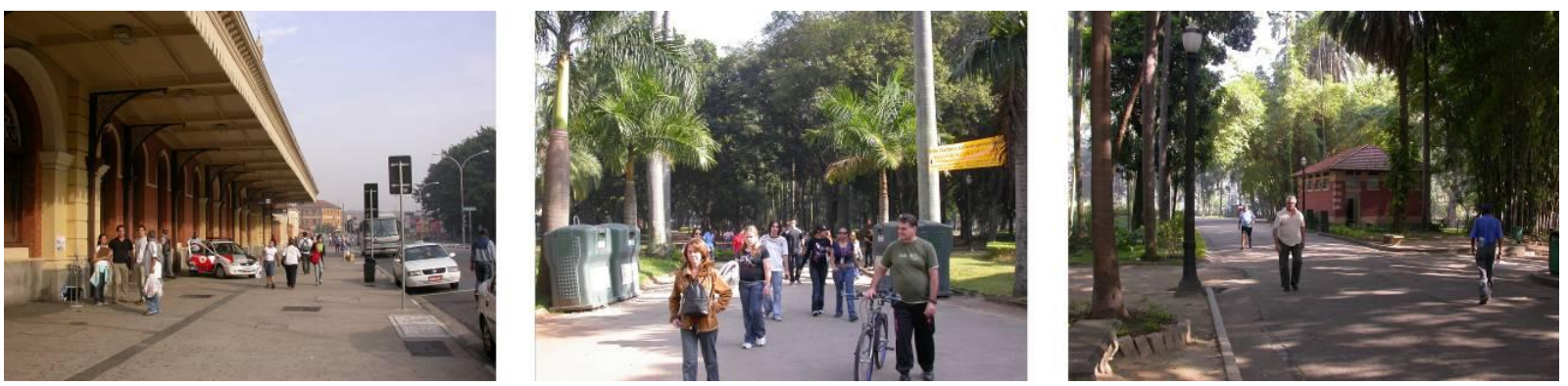

Figura 7 - Vista das bases levantadas empiricamente no Bairro da Luz no inverno
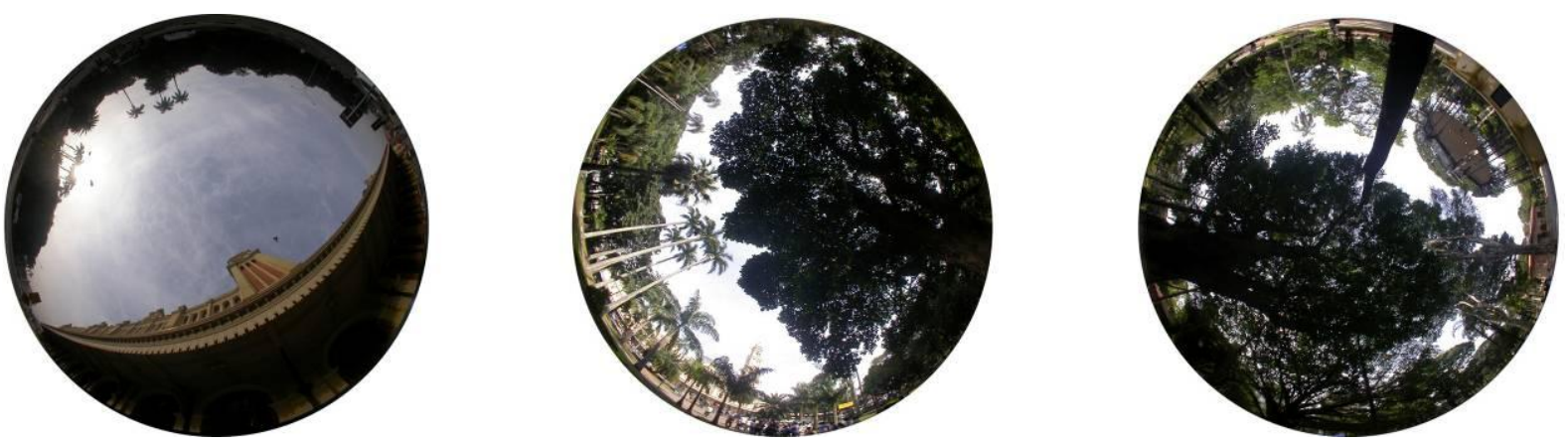

Figura 8 - Condições de exposição ao céu das bases no Bairro da Luz no inverno 


\section{Quantificação de variáveis}

\section{Variáveis ambientais}

As variáveis ambientais microclimáticas consideradas nesta pesquisa foram temperatura, umidade e velocidade do ar, e temperatura radiante média. A seguir, são considerados os critérios para sua determinação. Na sequência, têm-se os métodos e os procedimentos empregados para a quantificação física e matemática.

Para a quantificação física das variáveis ambientais, utilizou-se a norma ISO 7726 (1998), que traz as especificações dos instrumentos considerando duas classes de ambientes: moderados (tipo C: conforto) e com estresse térmico (tipo $\mathrm{S}$ : estresse). Utilizou-se tipo $\mathrm{C}$, seguindo Monteiro e Alucci (2005). A realização da quantificação de variáveis deve levar em consideração sua homogeneidade e heterogeneidade, assim como o caráter estacionário e variacional do tempo das grandezas medidas. Seguindo a referida norma, para critério de conforto, diz-se que um ambiente é homogêneo se verificado um erro, para cada medição com relação à média de todas as medições, de no máximo 3 vezes o valor da precisão requerida para temperatura do ar e de no máximo 2 vezes para as demais variáveis. Já para critério de estresse, admitem-se no máximo 4 vezes para temperatura do ar, 3 vezes para temperatura radiante média e 2 vezes para as demais variáveis. A precisão requerida das medidas é em relação à média. $\mathrm{O}$ caráter estacionário e transiente é avaliado de maneira análoga. Quando o ambiente é heterogêneo, as quantidades físicas devem ser medidas em diversos pontos, levando-se em conta os resultados parciais obtidos para se determinar o valor médio das quantidades a serem consideradas na avaliação do conforto ou do estresse térmico. A ISO 7726 (1998) apresenta as posições a serem utilizadas na medição das quantidades físicas e os coeficientes de ponderação a serem usados no cálculo do valor médio dessas quantidades. Com base em resultados de Monteiro (2008), realizando pré-testes de medições nas três alturas recomendadas, ao longo de dias de verão e de inverno, verificou-se para diferentes tipologias distintas de espaços abertos que os ambientes ali configurados eram homogêneos. O autor ressalta que foram verificados alguns desvios apenas ligeiramente maiores do que o especificado pela norma para as variáveis temperatura radiante média e velocidade do ar nas medições realizadas a 0,1 m. Dessa forma, nos levantamentos realizados, devido aos resultados prévios de Monteiro (2008), realizaram-se medições apenas a $1,1 \mathrm{~m}$ de altura, uma vez que as atividades verificadas, com as pessoas sentadas ou em pé, implicavam medições apenas a $1,1 \mathrm{~m}$ e a $0,6 \mathrm{~m}$. Como se considerou que os ambientes são suficientemente homogêneos, não se fez distinção em relação à altura, tendo sido eleita a de $1,1 \mathrm{~m}$, pois a grande maioria dos usuários dos espaços exercia atividades em pé.

Com relação aos sensores para quantificação física, para determinação da temperatura do ar foram utilizados sensores do tipo semicondutor. A faixa de leitura é de $-20{ }^{\circ} \mathrm{C}$ a $+60{ }^{\circ} \mathrm{C}$, com resolução de $0,1^{\circ} \mathrm{C}$, precisão de $\pm 0,4{ }^{\circ} \mathrm{C}$, e tempo de resposta de $0,1{ }^{\circ} \mathrm{C} / \mathrm{s}$. Para a obtenção da umidade relativa, foram empregados sensores de capacitância. A faixa de leitura é de $10 \%$ a $95 \%$, com resolução de $0,1 \%$, precisão de $\pm 3 \%$ (a $25^{\circ} \mathrm{C}$, entre $30 \%$ e $95 \%$ ) e $\pm 5 \%$ (a $25^{\circ} \mathrm{C}$, entre $10 \%$ e $30 \%$ ), e tempo de resposta de 3 min para mudança de $45 \%$ a $95 \%$, e de 5 min para o inverso. Quanto à velocidade do vento, utilizaram-se sensores de velocidade do ar compostos de copo (magnitude) e pá (direção/sentido), apresentando faixa de leitura de $0,3 \mathrm{~m} / \mathrm{s}$ a $30,0 \mathrm{~m} / \mathrm{s}$, resolução de $0,1 \mathrm{~m} / \mathrm{s}$ e precisão de $\pm 2 \%+d$. Por fim, com relação à temperatura radiante média, essa foi estimada a partir de medições de temperatura de globo, tendo sido utilizados globos de $10 \mathrm{~cm}$ de diâmetro, preto fosco e cinza médio fosco, com emissividade de aproximadamente 0,95. Para determinação da temperatura do ar no centro do globo, foram utilizados sensores do tipo semicondutor, com faixa de leitura de $-20{ }^{\circ} \mathrm{C}$ a $+60{ }^{\circ} \mathrm{C}$, resolução de $0,1{ }^{\circ} \mathrm{C}$, precisão de $\pm 0,4{ }^{\circ} \mathrm{C}$, e tempo de resposta de $0,1{ }^{\circ} \mathrm{C} / \mathrm{s}$. Com relação ao desempenho do sistema, segundo a ISO 7726 (1998), o tempo de resposta de um termômetro de globo é de aproximadamente $20 \mathrm{~min}$ a $30 \mathrm{~min}$, dependendo das características do globo e do ambiente em avaliação.

A quantificação matemática da temperatura radiante média é aqui explicitada. Considerando-se as quantificações físicas das variáveis anteriormente elencadas, para o cálculo da temperatura radiante média, realiza-se o balanço das trocas térmicas entre o globo e o ambiente em questão, considerando-se a temperatura do ar no centro do globo, a temperatura e a velocidade do ar no ambiente. Como resultado, têm-se as formulações para convecção natural e convecção forçada (ISO, 1998).

\section{Variáveis individuais}

As variáveis individuais levantadas na pesquisa empírica foram taxa metabólica e resistência térmica da roupa. Além da estimativa desses valores, consideraram-se o trabalho mecânico e a resistência evaporativa da roupa, associados 
respectivamente à taxa metabólica e à resistência térmica da roupa. Na sequência, apresentam-se os critérios utilizados, seguidos dos métodos e procedimentos empregados para sua quantificação. Considerando-se os valores de taxa metabólica apresentados por Fanger (1972) e ISO 8996 (1990), e ainda observando as atividades realizadas pelas pessoas ao longo dos pré-testes realizados nos locais dos levantamentos empíricos, determinaram-se valores para as taxas metabólicas em função das atividades observadas. Quando da aplicação do questionário de avaliação subjetiva das condições térmicas ambientais, o entrevistador tomava nota da atividade que a pessoa estava exercendo. Para interferir o mínimo possível na atividade em execução, os entrevistadores realizavam a mesma atividade que os entrevistados vinham realizando, para execução do questionário. Devido a observações feitas nos pré-testes, simplificou-se a anotação da atividade, utilizandose apenas quatro valores referenciais para as seis atividades observadas, conforme a Tabela 3 .

Dessa forma, os levantamentos consideram grupos de dados referentes a atividades metabólicas médias de 1,0, 1,3, 2,0 e 5,8 Met. Com relação à eficiência mecânica, devido às atividades verificadas, ela é desprezível, adotando-se valor igual a zero. Com relação aos valores de isolamento térmico, da resistência evaporativa e do fator de roupa, utilizou-se a escala da Figura 10, para que o entrevistador tomasse nota do conjunto de vestimentas que o entrevistado estava usando. Ressalta-se que as imagens referentes à figura em questão foram adaptadas da norma ISO 9920 (1995), em que cada peça de roupa está associada a um fator de roupa. Nesta pesquisa, consideraramse os valores tabelados de resistência térmica da roupa, adaptado da ISO 9920 (1995) e da ASHRAE (2005), e ainda as relações entre estes e a resistência evaporativa das roupas e os fatores de roupa. Assim, os valores apresentados na figura já fazem referência ao isolamento térmico estimado em clo, tendo sido a resistência evaporativa da roupa e o fator de roupa calculados conforme as formulações apresentadas na norma.

\section{Variáveis subjetivas}

As variáveis subjetivas quantificadas nesta pesquisa dizem respeito à percepção de sensação térmica e conforto térmico. O levantamento das respostas subjetivas se baseou nos princípios estabelecidos pela norma ISO 10551 (1995). No referido trabalho e na atual pesquisa, utilizam-se os critérios de ponto central e escalas de intensidades positivas e/ou negativas, quando aplicáveis. A norma em questão propõe um questionário com cinco perguntas padrão, as quais não foram transcritas diretamente para o português. Respeitando-se as peculiaridades linguísticas de cada idioma, optou-se por reinterpretar as cinco perguntas originais em língua inglesa, dando origem a um questionário em língua portuguesa com quatro questões. Além dessas quatro questões de avaliação global do ambiente, propõem-se outras quatro para a verificação da percepção e preferência relativas às variáveis ambientais específicas. A figura a seguir traz as questões relativas à avaliação subjetiva do questionário proposto e aplicado nos levantamentos laboratoriais.

No experimento laboratorial, havia certo controle dos sujeitos durante o levantamento, possibilitando que eles respondessem satisfatoriamente a um questionário impresso com oito itens. Nos levantamentos de campo, em situações urbanas reais, foi necessário restringir o número de questões, devido à necessidade de brevidade do questionário, para não comprometer as atividades realizadas nos ambientes levantados e para que se conseguisse efetivamente uma amostra significativa. Assim, optou-se por realizar apenas os dois primeiros itens do questionário original, acerca da percepção global do ambiente em termos de sensação térmica e conforto térmico.

\begin{tabular}{c|l|c}
\hline Valor de referência & \multicolumn{1}{|c|}{ Atividade } & Taxa metabólica (Met) \\
\hline $\mathbf{0}$ & Sentado & 1,0 \\
\hline $\mathbf{1}$ & Em pé, com pouca atividade & 1,3 \\
\hline $\mathbf{2}$ & Locomovendo-se lentamente & 1,6 \\
\hline & Andando relaxadamente $(3,2 \mathrm{~km} / \mathrm{h})$ & 2,0 \\
\hline $\mathbf{3}$ & Caminhando normalmente $(4,0 \mathrm{~km} / \mathrm{h})$ & 2,4 \\
\hline
\end{tabular}

Tabela 3 - Valores referenciais para determinação da taxa metabólica 
1. Neste exato momento, eu estou sentindo:

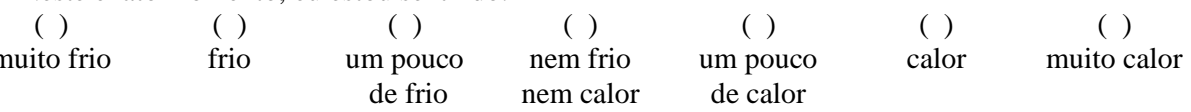

2. Neste exato momento, com relação às condições climáticas, eu estou:
( )
confortável
( )
um pouco
( )
desconfortável
( )
muito desconfortável
desconfortável

3. Neste exato momento, eu preferiria estar sentindo:

$\begin{array}{ccccccc}() & () & () & () & () & (~) & () \\ \text { muito mais } & \text { mais } & \text { um pouco } & \text { sem } & \text { um pouco mais } & \text { mais } & \text { muito mais } \\ \text { frio } & \text { frio } & \text { mais de frio } & \text { mudanças } & \text { de calor } & \text { calor } & \text { calor }\end{array}$

4. Neste exato momento, com relação às condições climáticas, na minha opinião estar neste local é:

$\begin{array}{cccc}() & () & (~ & (~) \\ \text { perfeitamente } & \text { facilmente } & \text { dificilmente } & \text { intolerável } \\ \text { tolerável } & \text { tolerável } & \text { tolerável }\end{array}$

5. Com relação à temperatura do ar, eu preferiria que essa estivesse:

( ) mais baixa

( ) como está

( ) mais alta

( ) não sei

6. Com relação à umidade do ar, $\begin{array}{llll}\text { eu preferiria que o ar estivesse: } & \text { ( ) mais seco } & \text { ( ) como está } & \text { ( ) mais úmido }\end{array}$

7. Com relação ao vento,

eu preferiria que esse estivesse: ( ) mais fraco $\quad$ ( ) como está $\quad$ ( ) mais forte $\quad$ ( ) não sei

8. Com relação à radiação solar, eu preferiria que essa estivesse: ( ) mais branda $\quad$ ( ) como está $\quad$ ( ) mais intensa $\quad$ ( ) não sei

Figura 9 - Questionário de percepção e preferência de sensação térmica aplicado nos levantamentos laboratoriais

Após a realização de pré-testes com diversos modelos de questionários, utilizando-se diferentes abordagens para a realização das perguntas, optouse pelo modelo da Figura 10. Para a quantificação das variáveis subjetivas de percepção foram estabelecidas duas questões, uma para verificação de sensação térmica e outra para a de conforto térmico. Dependendo das respostas, havia uma segunda questão subsequente a cada uma delas. Para verificar a sensação térmica, a primeira questão realizada pelo entrevistador era por meio da pergunta "Neste momento, aqui, você está com frio, calor ou nenhum dos dois?". Se o entrevistado respondesse "frio" ou "calor", havia então a segunda questão: "Você está com pouco calor (frio), mais ou menos, ou muito calor (frio)?". Para verificar o conforto térmico, o entrevistador repetia a resposta da pessoa da(s) questão(ões) anterior(es), perguntando: "Com relação a esse pouco calor (muito frio, neutralidade, etc.), você está confortável ou desconfortável?". Se o entrevistado respondesse "desconfortável", havia então uma segunda pergunta: "Você está pouco, mais ou menos ou muito desconfortável?".

Para a anotação das respostas, foram utilizados os critérios de ponto central e escalas de intensidades positivas e/ou negativas, quando aplicáveis. As questões de percepção de sensação térmica e de conforto térmico foram, cada uma delas, desmembradas em duas questões subsequentes e dependentes, pois dessa forma se facilitava a aplicação do questionário. Assim, a primeira pergunta possibilita uma resposta com valor positivo, negativo ou igual a zero. A segunda pergunta possibilita, caso a primeira pergunta apresente valor positivo ou negativo, a quantificação desse valor, "1", “2” ou "3”, respectivamente representando "pouco", "mais ou menos" e "muito".

\section{Outras variáveis}

Nos levantamentos laboratoriais também foi aplicado um questionário inicial para verificação de informações pessoais (sexo, idade, altura, peso) e verificação da aclimatação, perguntando-se sobre as cidades em que já viveu e por quanto tempo. Devido às características já elencadas dos levantamentos de campo, realizaram-se simplificações acerca da verificação da aclimatação, perguntando apenas a cidade/estado em que nasceu e há quanto tempo está na região metropolitana de São Paulo. Com relação às informações pessoais, essas foram estimadas pelos entrevistadores, conforme a Figura 10. Ressalta-se que o número de perguntas é pequeno, sendo restrito de quatro a seis dependendo das respostas das pessoas e que as perguntas são extremamente 
objetivas, sendo as respostas ou repetições de parte das perguntas ou informações muito fáceis de serem fornecidas. Assim, a realização inicial de uma explicação ou solicitação de autorização mostrou-se, nos pré-testes, inibidora ou demandante de tempo consideravelmente longo, tendo sido, por isso, descartada nos levantamentos efetivos.

Data: Período: Local:

Entrevistador:

1a) Neste momento, aqui: Você está com frio, calor ou nenhum dos dois?

1b) Se responder frio ou calor: Você está com pouco calor, mais ou menos, ou muito calor (frio)?

2a) Com relação a esse "pouco calor/muito frio/etc" (repetir a resposta da pessoa da questão 1) Você está confotável ou desconfotável?

2b) Se responder desconfortável: Você está pouco, mais ou menos ou muito desconfortável?

\begin{tabular}{|cl|}
\hline 3 muito calor \\
2 calor \\
1 pouco calor \\
0 neutra \\
-1 pouco frio \\
-2 frio \\
-3 muito frio \\
\hline 3 muito desconfortável \\
2 desconfortável \\
1 pouco desconfortável \\
0 confortável \\
\hline
\end{tabular}

3) Onde você nasceu? (Se for do estado de SP, anotar a cidade, se for de fora, anotar o estado)

4) Há quanto tempo você mora aqui na Grande São Paulo? (Se a pessoa não morar aqui, anotar há quanto tempo está aqui)

\begin{tabular}{|c|c|c|c|c|}
\hline & $\begin{array}{l}\text { Sens } \\
-3 \sim 3\end{array}$ & $\begin{array}{l}\text { Conf } \\
0 \sim 3\end{array}$ & $\begin{array}{l}\text { Nascimento } \\
\text { Cidade/Estado }\end{array}$ & $\begin{array}{l}\text { Tempo vivendo } \\
\text { na Grande SP }\end{array}$ \\
\hline 01 & & & & \\
\hline 02 & & & & \\
\hline 03 & & & & \\
\hline 04 & & & & \\
\hline 05 & & & & \\
\hline 06 & & & & \\
\hline 07 & & & & \\
\hline 08 & & & & \\
\hline 09 & & & & \\
\hline 10 & & & & \\
\hline 11 & & & & \\
\hline 12 & & & & \\
\hline 13 & & & & \\
\hline 14 & & & & \\
\hline 15 & & & & \\
\hline 16 & & & & \\
\hline 17 & & & & \\
\hline 18 & & & & \\
\hline 19 & & & & \\
\hline 20 & & & & \\
\hline
\end{tabular}

\begin{tabular}{|c|c|c|c|c|c|c|}
\hline $\begin{array}{l}\text { Iclo } \\
0,3 \sim 0,9 *\end{array}$ & $\begin{array}{l}\text { Cor } \\
\text { CME }\end{array}$ & $\begin{array}{l}\text { Idade } \\
\text { Aprox }\end{array}$ & $\begin{array}{l}\text { Sexo } \\
M / F\end{array}$ & $\begin{array}{l}\text { Ativ } \\
0 \sim 3\end{array}$ & $\begin{array}{l}\text { Sol? } \\
\text { S/N }\end{array}$ & $\begin{array}{l}\text { Horário } \\
\text { hh:mm }\end{array}$ \\
\hline & & & & & & \\
\hline & & & & & & \\
\hline & & & & & & \\
\hline & & & & & & \\
\hline & & & & & & \\
\hline & & & & & & \\
\hline & & & & & & \\
\hline & & & & & & \\
\hline & & & & & & \\
\hline & & & & & & \\
\hline & & & & & & \\
\hline & & & & & & \\
\hline & & & & & & \\
\hline & & & & & & \\
\hline & & & & & & \\
\hline & & & & & & \\
\hline & & & & & & \\
\hline & & & & & & \\
\hline & & & & & & \\
\hline & & & & & & \\
\hline
\end{tabular}
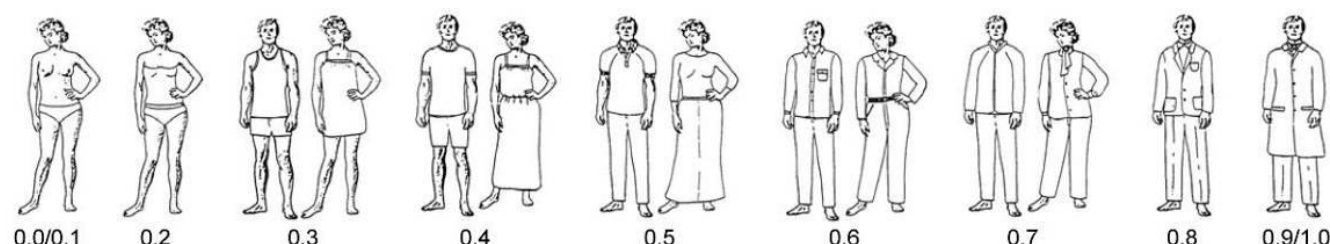

\begin{tabular}{|l|}
\hline $\begin{array}{l}\text { Cor predominate } \\
\text { da roupa }\end{array}$ \\
$\mathrm{C}=$ clara \\
$\mathrm{M}=$ média \\
$\mathrm{E}=$ escura
\end{tabular}
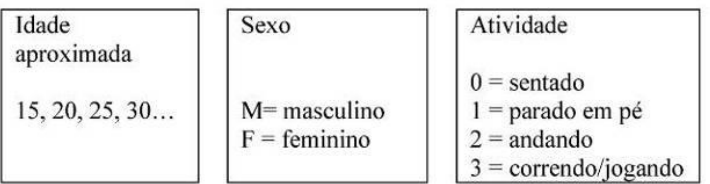

\begin{tabular}{|l|}
\hline O entrevistado estava \\
exposto ao sol? \\
$\mathrm{S}=\operatorname{sim}$ \\
$\mathrm{N}=$ não
\end{tabular}

Figura 10 - Instruções e tabela de anotação de variáveis subjetivas e individuais 


\section{Verificação comparativa}

Tem-se aqui a apresentação das simulações computacionais dos modelos preditivos, considerando-se os índices originalmente apresentados pelos autores e os resultados com as calibrações propostas com base nos resultados obtidos por meio das bases empíricas na Cidade Universitária (caráter laboratorial) e no Bairro da Luz (levantamentos de campo).

A Tabela 4 traz os modelos utilizados para as simulações, assim como as referências bibliográficas em que podem ser encontradas suas formulações matemáticas. Apresenta ainda as diversas variáveis que são consideradas em cada um dos modelos. Os modelos foram processados computacionalmente em planilhas eletrônicas de cálculo, realizando-se sucessivamente a simulação com base nos índices originais e nos índices calibrados, seguindo critérios a serem apresentados. Em seguida, realizou-se a calibração dos modelos, por meio de proposição de novas faixas interpretativas, também seguindo critérios a serem apresentados.

\section{Critérios de comparação}

Para a realização da comparação entre os modelos, adotaram-se três critérios, que estão baseados na correlação entre os resultados de cada um dos modelos e respectivos índices e os resultados encontrados nos levantamentos empíricos, levando-se em consideração, assim como feito com os dados da Cidade Universitária, os valores médios obtidos em cada uma das situações levantadas. Ressalta-se que, para os resultados da Cidade Universitária, foram estabelecidas 72 situações microclimáticas. Para o Bairro da Luz, têm-se 44 situações microclimáticas. As especificidades das situações microclimáticas e de seus dados individuais e subjetivos correlatos serão ainda objeto de publicação futura. Neste artigo, a verificação comparativa, para cada modelo, é realizada pela consideração dos resultados seguindo três critérios:

(a) a correlação entre os resultados do parâmetro adotado pelo modelo e os resultados, em termos de respostas subjetivas de percepção de sensação térmica, do levantamento empírico;

(b) a correlação entre os resultados do índice do modelo e os resultados, também em termos de respostas subjetivas de percepção de sensação térmica, do levantamento empírico; e

(c) a porcentagem de equivalência de respostas do índice para os casos em que haja a possibilidade de estabelecimento de correlação linguística entre as faixas interpretativas desse e as utilizadas no levantamento empírico.

Detalhes acerca da seleção de cada um dos critérios adotados encontram-se em Monteiro (2008).

\section{Critérios de calibração}

Os critérios para calibração dos índices dos modelos são originalmente propostos por Monteiro (2008) e são aqui sucintamente apresentados. Para cada índice interpretativo dos modelos, estabeleceu-se uma escala em termos de sensação térmica com sete valores: muito frio $(-3)$, frio $(-2)$, pouco frio $(-1)$, neutralidade $(0)$, pouco calor (1) calor (2) e muito calor (3), correspondendo linguisticamente ao estabelecido para a realização dos empíricos. Para a realização da calibração, utilizou-se método iterativo, variando-se os limites superiores e inferiores de cada faixa interpretativa, visando a maximizar a correlação entre os valores fornecidos por essas e os valores das respostas subjetivas de sensação térmica. Seria possível a calibração por meio da maximização da quantidade, em termos percentuais, de predições corretas, mas, ainda que com menor porcentagem de acertos, admitiu-se que maior correlação exprime mais significativamente a tendência para acertar outras predições. A iteração realizada considerou a mesma precisão de casas decimais apresentadas pelos índices originais. No caso dos índices de temperatura equivalente, considerou-se uma casa decimal. Para a proposição dos limites das faixas interpretativas, adotaram-se apenas valores inteiros ou meios, arredondando-se os valores originais. Assim como foi constatado por Monteiro (2008), também nas calibrações aqui realizadas os resultados apresentaram variação decimal, sem que com isso houvesse alteração na segunda casa decimal da correlação obtida. Da mesma forma, para uniformidade de critério e não indicação de precisões inexistentes, realizaram-se aproximações nos resultados dos demais índices sempre que também não houvesse alteração na segunda casa decimal da correlação encontrada. 


\begin{tabular}{|c|c|c|c|c|c|c|c|c|c|c|c|c|c|c|c|c|}
\hline \multirow{3}{*}{ Modelo } & \multirow{3}{*}{ Referência } & \multirow{3}{*}{ Índices } & \multicolumn{14}{|c|}{ Variáveis independentes } \\
\hline & & & \multicolumn{4}{|c|}{ individuais } & \multicolumn{4}{|c|}{$\begin{array}{c}\text { microclimá } \\
\text {-ticas }\end{array}$} & \multicolumn{2}{|c|}{$\begin{array}{c}\text { deri- } \\
\text { vadas }\end{array}$} & \multicolumn{4}{|c|}{ climáticas } \\
\hline & & & $\mathbf{M}$ & $\mathbf{W}$ & $\mathbf{I}_{\mathrm{cl}}$ & $\mathbf{R}_{\mathrm{e}}$ & $t_{\mathrm{ar}}$ & $\mathbf{p}_{\mathrm{ar}}$ & \begin{tabular}{|l|l|l} 
& $t$ \\
\end{tabular} & $\mathbf{t}_{\mathrm{rm}}$ & $\mathbf{t}_{\mathrm{g}}$ & $t_{\text {bu }}$ & $t_{\mathrm{bs}}$ & ur & $\mathbf{v}_{10}$ & $\mathbf{R}$ \\
\hline ET & $\begin{array}{l}\text { Houghten e Yaglou, 1923; } \\
\text { Szokolay, } 2001\end{array}$ & $\mathrm{ET}^{*}$ & & & & & $\mathrm{x}$ & $\mathrm{x}$ & & & & & & & & \\
\hline ET & $\begin{array}{l}\text { Vernom e Warner, 1932; } \\
\text { Szokolay, } 2001\end{array}$ & CET* $^{*}$ & & & & & $\mathrm{x}$ & $\mathrm{x}$ & & & $\mathrm{x}$ & & & & & \\
\hline OT & $\begin{array}{l}\text { Winslow, Herrington e } \\
\text { Gagge, 1937; ASHRAE, } \\
2005\end{array}$ & OT & & & & & $\mathrm{x}$ & & $\mathrm{x}$ & $\mathrm{x}$ & & & & & & \\
\hline $\mathrm{ET}+\mathrm{OT}$ & $\begin{array}{l}\text { ASHRAE, 1992, Szokolay, } \\
2001\end{array}$ & EOT $^{*}$ & & & & & $\mathrm{x}$ & $\mathrm{x}$ & $\mathrm{x}$ & $\mathrm{x}$ & & & & & & \\
\hline WCT & Siple e Passel, 1945 & WCTI & & & & & & & & & & & $\mathrm{x}$ & & $\mathrm{x}$ & \\
\hline HSI & Belding e Hatch, 1955 & HSI & & & & & $\mathrm{x}$ & $\mathrm{x}$ & $\mathrm{x}$ & $\mathrm{x}$ & & & & & & \\
\hline WBGT & $\begin{array}{l}\text { Yaglou e Minard, 1957; } \\
\text { ISO, } 1989\end{array}$ & WBGT & & & & & $\mathrm{x}$ & & & & $\mathrm{x}$ & $\mathrm{x}$ & & & & \\
\hline Gagge & $\begin{array}{l}\text { Gagge, Stolwijk e Hardy, } \\
1967\end{array}$ & SET $^{*}$ & $\mathrm{x}$ & $\mathrm{x}$ & $\mathrm{x}$ & $\mathrm{x}$ & $\mathrm{x}$ & $\mathrm{x}$ & $\mathrm{x}$ & $\mathrm{x}$ & & & & & & \\
\hline ITS & Givoni, 1969 & ITS & & & & & $\mathrm{x}$ & $\mathrm{x}$ & $\mathrm{x}$ & $\mathrm{x}$ & & & & & & \\
\hline Humidex & $\begin{array}{l}\text { Masterton e Richardson, } \\
1979\end{array}$ & $\mathrm{HU}$ & & & & & $\mathrm{x}$ & $\mathrm{x}$ & & & & & & & & \\
\hline KMM & $\begin{array}{l}\text { Jendritzky, 1979, 1991; } \\
\text { Fanger, } 1972\end{array}$ & PMV & $\mathrm{x}$ & $\mathrm{x}$ & $\mathrm{x}$ & $\mathrm{x}$ & $\mathrm{x}$ & $\mathrm{x}$ & $\mathrm{x}$ & $\mathrm{x}$ & & & & & & \\
\hline Vogt & ISO, 1989; Vogt et al., 1981 & Swreq & $\mathrm{x}$ & $\mathrm{x}$ & $\mathrm{x}$ & $\mathrm{x}$ & $\mathrm{x}$ & $\mathrm{x}$ & $\mathrm{x}$ & $\mathrm{x}$ & & & & & & \\
\hline “ & “ & $\mathrm{w}$ & $\mathrm{x}$ & $\mathrm{x}$ & $\mathrm{x}$ & $\mathrm{x}$ & $\mathrm{x}$ & $\mathrm{x}$ & $\mathrm{x}$ & $\mathrm{x}$ & & & & & & \\
\hline Sevilha & Dominguez et al., 1992 & Swreq' & $\mathrm{x}$ & $\mathrm{x}$ & $\mathrm{x}$ & $\mathrm{x}$ & $\mathrm{x}$ & $\mathrm{x}$ & $\mathrm{x}$ & $\mathrm{x}$ & & & & & & $\mathrm{x}$ \\
\hline COMFA & Brown e Gillespie, 1995 & $S^{\prime}$ & $\mathrm{x}$ & & $\mathrm{x}$ & & $\mathrm{x}$ & $\mathrm{x}$ & $\mathrm{x}$ & $\mathrm{x}$ & & & & & & \\
\hline Tne & $\begin{array}{l}\text { Aroztegui, 1995; } \\
\text { Humphreys } 1978\end{array}$ & Tne & & & & & & & & & & & $\mathrm{x}$ & & $\mathrm{x}$ & $\mathrm{x}$ \\
\hline MENEX & Blazejczyk, 1996; 2002 & HL & $\mathrm{x}$ & $\mathrm{x}$ & $\mathrm{x}$ & $\mathrm{x}$ & $\mathrm{x}$ & $\mathrm{x}$ & $\mathrm{x}$ & $\mathrm{x}$ & & & & & & \\
\hline “ & “ & $\mathrm{PhS}$ & $\mathrm{x}$ & $\mathrm{x}$ & $\mathrm{x}$ & $\mathrm{x}$ & $\mathrm{x}$ & $\mathrm{x}$ & $\mathrm{x}$ & $\mathrm{x}$ & & & & & & \\
\hline “" & “ & $\mathrm{R}^{\prime}$ & & & $\mathrm{x}$ & & & & & & & & & & & $\mathrm{x}$ \\
\hline “" & “" & STI & $\mathrm{x}$ & $\mathrm{x}$ & $\mathrm{x}$ & $\mathrm{x}$ & $\mathrm{x}$ & $\mathrm{x}$ & $\mathrm{x}$ & $\mathrm{x}$ & & & & & & \\
\hline “" & “ & SP & $\mathrm{x}$ & $\mathrm{x}$ & $\mathrm{x}$ & $\mathrm{x}$ & $\mathrm{x}$ & $\mathrm{x}$ & $\mathrm{x}$ & $\mathrm{x}$ & & & & & & \\
\hline “" & “6 & ECI & & & & & $\mathrm{x}$ & & & & & & & & & \\
\hline De Freitas & Freitas, 1997 & PSI & $\mathrm{x}$ & $\mathrm{x}$ & $\mathrm{x}$ & $\mathrm{X}$ & $\mathrm{x}$ & $\mathrm{x}$ & $\mathrm{x}$ & $\mathrm{x}$ & & & & & & \\
\hline “" & “ & STE & $\mathrm{x}$ & $\mathrm{x}$ & $\mathrm{x}$ & $\mathrm{x}$ & $\mathrm{x}$ & $\mathrm{x}$ & $\mathrm{x}$ & $\mathrm{x}$ & & & & & & \\
\hline MEMI & Höppe, 1999 & PET & $\mathrm{x}$ & $\mathrm{x}$ & $\mathrm{x}$ & $\mathrm{x}$ & $\mathrm{x}$ & $\mathrm{x}$ & $\mathrm{x}$ & $\mathrm{x}$ & & & & & & \\
\hline TS & Givoni e Noguchi, 2000 & TS & & & & & $\mathrm{x}$ & $\mathrm{x}$ & $\mathrm{x}$ & $\mathrm{x}$ & & & & & & $\mathrm{x}$ \\
\hline NWCT & Bluestein e Osczevski, 2002 & $\begin{array}{l}\text { NWCT } \\
\text { I }\end{array}$ & & & & & & & & & & & $\mathrm{x}$ & & $\mathrm{x}$ & \\
\hline ASV & Nikolopoulou, 2004 & ASV & & & & & & & & & & & $\mathrm{x}$ & $\mathrm{x}$ & $\mathrm{x}$ & $\mathrm{x}$ \\
\hline TEP & Monteiro, 2008 & TEP & $\mathrm{x}$ & & $\mathrm{x}$ & & $\mathrm{x}$ & $\mathrm{x}$ & $\mathrm{x}$ & $\mathrm{x}$ & & & $\mathrm{x}$ & & & \\
\hline
\end{tabular}

Tabela 4 - Modelos preditivos, índices e respectivas variáveis para simulação computacional 


\begin{tabular}{c|c|c|c|c}
\hline \multirow{2}{*}{ Variável } & \multicolumn{2}{|c|}{ Cidade Universitária } & \multicolumn{2}{c}{ Bairro da Luz } \\
\cline { 2 - 5 } & $\begin{array}{c}\text { Mínimo } \\
\text { observado }\end{array}$ & $\begin{array}{c}\text { Máximo } \\
\text { observado }\end{array}$ & $\begin{array}{c}\text { Mínimo } \\
\text { observado }\end{array}$ & $\begin{array}{c}\text { Máximo } \\
\text { observado }\end{array}$ \\
\hline $\left.\mathbf{t}_{\mathbf{a r}} \mathbf{(} \mathbf{(}^{\mathbf{0}} \mathbf{C}\right)$ & 15,1 & 33,1 & 17,4 & 33,7 \\
\hline $\mathbf{U R}(\boldsymbol{\%})$ & 31 & 95 & 35 & 85 \\
\hline $\mathbf{v}_{\mathbf{a r}}(\mathbf{m} / \mathbf{s})$ & 0,1 & 3,6 & 0,1 & 2,7 \\
\hline $\left.\mathbf{t}_{\mathbf{r m}} \mathbf{(} \mathbf{0} \mathbf{C}\right)$ & 15,5 & 65,5 & 17,4 & 47,8 \\
\hline $\mathbf{I}_{\mathbf{c l}}(\mathbf{c l o})$ & 0,26 & 1,17 & 0,30 & 0,90 \\
\hline $\mathbf{M}(\mathbf{m e t})$ & 1,3 & 1,3 & 1,0 & 5,8 \\
\hline
\end{tabular}

Tabela 5 - Valores-limite das variáveis ambientais e pessoais

\section{Valores-limite}

A fim de se elucidar a validade das simulações realizadas, a Tabela 5 apresenta comparativamente os valores-limite observados nos levantamentos laboratoriais na Cidade Universitária e nos levantamentos de campo no Bairro da Luz.

Ressalta-se que os valores verificados nas situações microclimáticas do Bairro da Luz estão dentro dos limites verificados para a Cidade Universitária, possibilitando, assim, a adequada verificação dos resultados obtidos com essa base empírica, uma vez que aquela base está dentro dos valores-limite desta. Ressalva deve ser feita para a temperatura do ar, que apresenta valor ligeiramente superior nos dados observados no Bairro da Luz. Poderia ter sido feita opção pela retirada dessa situação microclimática limite. Contudo, devido à pequena diferença encontrada, assumiu-se que a extrapolação em questão é aceitável. Com relação aos valores do isolamento da roupa, todos os valores encontrados para o Bairro da Luz estão dentro dos limites dos encontrados na Cidade Universitária. Observa-se ainda que os limites superiores de isolamento da roupa são significativamente inferiores aos encontrados no levantamento laboratorial. Por fim, referente à taxa metabólica, deve ser observado que os levantamentos laboratoriais na Cidade Universitária consideraram apenas um único tipo de atividade, tendo sido as variações de taxa metabólica consideradas apenas por meio de modelos teóricos. A implicação da consideração de diferentes taxas metabólicas será verificada em publicação futura.

\section{Resultados e discussão}

Para a discussão dos resultados, um primeiro conjunto se refere aos levantamentos empíricos da Cidade Universitária, e um segundo conjunto, referente aos do Bairro da Luz. No primeiro conjunto, são considerados dois subconjuntos, referentes aos índices originais e aos calibrados, tendo-se como referência a base empírica da
Cidade Universitária. No segundo conjunto, há três subconjuntos, referentes aos índices originais e aos calibrados respectivamente pelas bases da Cidade Universitária e do Bairro da Luz.

Assim, nas Tabelas 6 a 12 têm-se:

(d) Io = índices originais;

(e) Ic,c = índices calibrados com dados levantados na Cidade Universitária;

(f) Ic, b = índices calibrados com dados levantados no Bairro da Luz;

(g) $\mathrm{Cpm}=$ correlação com o parâmetro do modelo;

(h) Cfi = correlação com as faixas interpretativas; e

(i) \%ap $=$ porcentagem de acertos preditivos.

A discussão dos resultados é realizada utilizandose a classificação de Monteiro e Alucci (2007). Assim, configuram-se dois grandes grupos, segundo o objeto de predição do modelo esforço fisiológico e sensação térmica. Cada grupo está subdivido em três subgrupos. Não se considerou a classificação segundo o método predominante do modelo, pois as comparações são mais facilmente realizadas segundo os critérios interpretativos dos índices, tendo sido esses os utilizados.

Para facilitar o acompanhamento das considerações, são reapresentados os resultados da tabela anterior, com os módulos das correlações entre resultados do levantamento de campo e resultados das simulações para base empírica da Cidade Universitária e do Bairro da Luz, para cada um dos seis subgrupos, por meio de uma nova tabela, com apenas os resultados pertinentes à discussão.

\section{Modelos de esforço fisiológico}

Para a consideração dos resultados dos índices baseados em modelos de esforço fisiológico, ou comumente denominados como índices de estresse térmico, três subgrupos são definidos: 
(a) índices normativos de estresse térmico;

(b) índices de estresse térmico por calor; e

(c) índices de estresse térmico por calor e frio.

Essa subdivisão foi estabelecida por Monteiro e Alucci (2007) e é aqui mantida, facilitando-se a discussão dos resultados. Consideram-se, assim, inicialmente, as ferramentas normativas passíveis de serem aplicadas a espaços abertos. Em seguida, são considerados os demais índices que verificam apenas situações térmicas quentes. Por fim, têm-se os índices que abrangem situações térmicas quentes e frias. Os índices WCTI e NWCTI são índices relativos à exposição a situações térmicas frias, mas são considerados juntamente com o terceiro subgrupo, justificando-se $o$ fato na discussão do referido subgrupo.

\section{Índices normativos de estresse térmico}

As normas ISO 7243 (1989), NR-15 (BRASIL, 1978) e ISO 7933 (1989) são aqui consideradas, e os resultados de seus modelos e respectivos índices podem ser observados na Tabela 6 .

Considerando os resultados encontrados, observase que, segundo a norma ISO 7243 (1989), todas as situações analisadas não oferecem risco de estresse por calor para aclimatados ou não aclimatados. A norma NR-15 (BRASIL, 1979) também indica o mesmo resultado, permitindo, no caso específico de atividades laborais, trabalho contínuo. A norma ISO 7933 (1989) também não indicou restrição em seus critérios de estresse térmico (Swreq e w) ou de esforço fisiológico ( $\mathrm{S}$ e Swreq em g/h). Observa-se, segundo os critérios da norma, que na situação mais crítica o tempo de atenção e o tempo-limite são de $6,7 \mathrm{~h}$ e de $8,3 \mathrm{~h}$ para não aclimatados e de 10,0 h e 13,4 h para aclimatados. Em suma, considerando-se os resultados das normas em questão, pode-se afirmar que nenhuma das situações em análise apresenta estresse térmico.
Assim, baseando-se nessas três normas, que fornecem informações acerca do risco de estresse térmico, a única conclusão possível de ser obtida por meio delas é que as situações em análise não apresentam esse risco. Contudo, apesar de as referidas situações não fazerem parte da faixa de avaliação qualitativa dessas normas, é interessante observar a alta correlação positiva encontrada entre o WBGT, o Swreq e o w e o valor médio das respostas de percepção de sensação térmica, não somente para o caso laboratorial da Cidade Universitária $(0,80,0,86$ e 0,84$)$, mas também para as situações urbanas reais no Bairro da Luz $(0,83$, $0,82$ e 0,77$)$.

Com relação aos índices calibrados, observa-se que, em relação à base empírica da Cidade Universitária, os resultados são mais significativos $(0,82,0,85$ e 0,83$)$ do que em relação à da base do Bairro da Luz $(0,77,0,81$ e 0,65$)$. A nova calibração proposta apresenta apenas pequena melhora nos resultados $(0,80,0,83$ e 0,66$)$. Com relação aos resultados finais em termos de acertos preditivos, a porcentagem é mais significativa para o caso da Cidade Universitária (77\%, 76\% e 76\%) do que para o Bairro da Luz (55\%, 57\% e 53\%).

\section{Índices de estresse térmico por calor}

São considerados aqui o HSI, HU, Swreq (Sevilha), R' e SP. Os resultados correlativos e em termos de acertos preditivos podem ser observados na Tabela 7.

A menor correlação encontrada para a Cidade Universitária foi a do HU (0,65 para o parâmetro do modelo e 0,60 para a interpretação do índice). Os resultados foram ainda menos significativos para o Bairro da Luz (0,56 para o parâmetro do modelo e 0,55 e 0,57 para a interpretação do índice original e calibrado respectivamente). Os resultados pouco significativos devem-se provavelmente ao fato de esse índice considerar apenas as variáveis temperatura e umidade do ar.

\begin{tabular}{|c|c|c|c|c|c|c|c|c|c|c|c|c|c|}
\hline \multirow{2}{*}{\multicolumn{2}{|c|}{$\begin{array}{l}\text { Base empírica } \\
\text { Calibração }\end{array}$}} & \multicolumn{5}{|c|}{ Cidade Universitária } & \multicolumn{7}{|c|}{ Bairro da Luz } \\
\hline & & \multirow[b]{2}{*}{ Cpm } & \multicolumn{2}{|c|}{ lo } & \multicolumn{2}{|c|}{ Ic,C } & \multirow[b]{2}{*}{ Cpm } & \multicolumn{2}{|c|}{ lo } & \multicolumn{2}{|c|}{ Ic,C } & \multicolumn{2}{|c|}{ Ic,b } \\
\hline Modelo & Índices & & Cfi & $\%$ ap & Cfi & $\%$ ap & & Cfi & \%ap & Cfi & \%ap & Cfi & \%ap \\
\hline WBGT & WBGT & 0,80 & - & - & 0,82 & $77 \%$ & 0,83 & - & - & 0,77 & $43 \%$ & 0,80 & $55 \%$ \\
\hline Vogt & Swreq & 0,86 & - & - & 0,85 & $76 \%$ & 0,82 & - & - & 0,81 & $59 \%$ & 0,83 & $57 \%$ \\
\hline “ & $\mathbf{w}$ & 0,84 & - & - & 0,83 & $76 \%$ & 0,77 & - & - & 0,65 & $53 \%$ & 0,66 & $53 \%$ \\
\hline
\end{tabular}

Tabela 6 - Resultados para índices normativos de estresse térmico 


\begin{tabular}{|c|c|c|c|c|c|c|c|c|c|c|c|c|c|}
\hline \multirow{2}{*}{\multicolumn{2}{|c|}{$\begin{array}{c}\text { Base empírica } \\
\text { Calibração }\end{array}$}} & \multicolumn{5}{|c|}{ Cidade Universitária } & \multicolumn{7}{|c|}{ Bairro da Luz } \\
\hline & & \multirow[b]{2}{*}{ Cpm } & \multicolumn{2}{|c|}{ Io } & \multicolumn{2}{|c|}{ Ic,c } & \multirow[b]{2}{*}{ Cpm } & \multicolumn{2}{|c|}{ Io } & \multicolumn{2}{|c|}{ Ic,c } & \multicolumn{2}{|c|}{ Ic,b } \\
\hline Modelo & Índices & & Cfi & $\%$ ap & Cfi & $\%$ ap & & Cfi & $\%$ ap & Cfi & $\%$ ap & Cfi & $\%$ ap \\
\hline HSI & HSI & 0,80 & 0,74 & $64 \%$ & 0,83 & $78 \%$ & 0,74 & 0,66 & $14 \%$ & 0,68 & $43 \%$ & 0,69 & $48 \%$ \\
\hline Humidex & HU & 0,65 & 0,61 & $51 \%$ & 0,69 & $61 \%$ & 0,56 & 0,55 & $25 \%$ & 0,55 & $49 \%$ & 0,57 & $43 \%$ \\
\hline Sevilha & Swreq' & 0,88 & 0,84 & $72 \%$ & 0,88 & $78 \%$ & 0,81 & 0,60 & $45 \%$ & 0,82 & $57 \%$ & 0,85 & $64 \%$ \\
\hline MENEX & $\mathbf{R}^{\prime}$ & 0,87 & 0,75 & $67 \%$ & 0,85 & $78 \%$ & 0,74 & 0,43 & $18 \%$ & 0,55 & $18 \%$ & 0,56 & $24 \%$ \\
\hline “6 & SP & 0,86 & 0,82 & $72 \%$ & 0,85 & $71 \%$ & 0,76 & 0,66 & $52 \%$ & 0,70 & $48 \%$ & 0,73 & $55 \%$ \\
\hline
\end{tabular}

Tabela 7 - Resultados para índices de estresse térmico por calor

\begin{tabular}{|c|c|c|c|c|c|c|c|c|c|c|c|c|c|}
\hline \multirow{2}{*}{\multicolumn{2}{|c|}{$\begin{array}{c}\text { Base empírica } \\
\text { Calibração }\end{array}$}} & \multicolumn{5}{|c|}{ Cidade Universitária } & \multicolumn{7}{|c|}{ Bairro da Luz } \\
\hline & & \multirow[b]{2}{*}{ Cpm } & \multicolumn{2}{|c|}{ Io } & \multicolumn{2}{|c|}{ Ic,c } & \multirow[b]{2}{*}{ Cpm } & \multicolumn{2}{|c|}{ Io } & \multicolumn{2}{|c|}{ Ic,c } & \multicolumn{2}{|c|}{ Ic,b } \\
\hline Modelo & Índices & & Cfi & $\%$ ap & Cfi & $\%$ ap & & Cfi & $\%$ ap & Cfi & $\%$ ap & Cfi & $\%$ ap \\
\hline WCT & WCTI & 0,72 & 0,68 & $25 \%$ & 0,73 & $71 \%$ & 0,70 & 0,60 & $14 \%$ & 0,63 & $32 \%$ & 0,64 & $35 \%$ \\
\hline ITS & ITS & 0,86 & 0,76 & $58 \%$ & 0,86 & $81 \%$ & 0,75 & 0,65 & $43 \%$ & 0,73 & $48 \%$ & 0,75 & $55 \%$ \\
\hline MENEX & HL & 0,88 & 0,83 & $63 \%$ & 0,87 & $83 \%$ & 0,86 & 0,76 & $41 \%$ & 0,85 & $64 \%$ & 0,86 & $68 \%$ \\
\hline “ & PhS & 0,82 & 0,77 & $31 \%$ & 0,88 & $81 \%$ & 0,78 & 0,78 & $52 \%$ & 0,74 & $43 \%$ & 0,78 & $55 \%$ \\
\hline NWCT & $\begin{array}{c}\text { NWCT } \\
\text { I }\end{array}$ & 0,68 & 0,64 & $18 \%$ & 0,69 & $64 \%$ & 0,58 & 0,54 & $15 \%$ & 0,58 & $25 \%$ & 0,59 & $30 \%$ \\
\hline
\end{tabular}

Tabela 8 - Resultados para índices de estresse térmico por calor e frio

A correlação dos demais índices foi mais significativa, mas de todos os resultados foram inferiores ao encontrado laboratorialmente na Cidade Universitária. O HSI, R' e SP são modelos de balanço térmico que apresentaram resultados de correlação do parâmetro de seus modelos entre 0,74 e 0,76 no Bairro da Luz, contra valores superiores a 0,80 na Cidade Universitária. É interessante observar que as correlações com as faixas interpretativas dos modelos são bem menos significativas no caso do Bairro da Luz, de 0,55 a 0,70, contra 0,74 a 0,82 para a Cidade Universitária. Assim como no caso dos índices normativos, verifica-se que a calibração específica para o Bairro da Luz não apresenta significativa melhora nos resultados, variando de 0,56 a 0,73 , e ainda apresentando porcentagens de acertos preditivos baixas, de $24 \%$ a $48 \%$, contra $71 \%$ a $78 \%$ no caso da Cidade Universitária.

Por fim, o modelo de Sevilha foi o índice de estresse térmico por calor que apresentou os melhores resultados. Ainda que para o caso da Cidade Universitária eles fossem ainda mais significativos $(0,88,0,88$ e $78 \%$, considerando o modelo calibrado com a base empírica local), para o Bairro da Luz apresentou o melhor resultado entre os índices, inclusos os normativos, de estresse térmico por calor $(0,81,0,85$ e $64 \%$, considerando o modelo calibrado com a base empírica local, no Bairro da Luz). O índice de Sevilha apresenta uma proposta que caracteriza o uso do espaço em função do esforço fisiológico. Dados os resultados do índice, essa questão pode ser explorada para se determinarem as possibilidades de uso dos diferentes espaços abertos urbanos.

\section{Índices de estresse térmico por calor e frio}

Os índices WCTI, NWCTI, ITS, PhS e HL são aqui considerados. Os resultados em termos de correlação e de acertos preditivos podem ser observados na Tabela 8 .

Conforme já apontado em Monteiro (2008), os índices WCTI e NWCTI são de estresse térmico por frio, avaliando apenas o efeito do vento e a temperatura do ar. Contudo, como comumente se apresentam tabelas de interpretação de seus valores também para temperaturas mais elevadas, são aqui considerados como índices de estresse térmico por calor e frio. Os resultados, porém, indicaram os mais baixos índices de correlação $(0,70$ e 0,58 para o parâmetro do modelo, 0,60 e 0,54 para a interpretação do índice original, e 0,63 e 0,58 e 
0,64 e 0,59 para o caso das calibrações na Cidade Universitária e no Bairro da Luz respectivamente). Deve-se observar que as calibrações específicas no Bairro da Luz apresentaram ganho correlativo não significante. Observa-se ainda que o modelo original, WCTI, apresentou resultados mais significativos do que a nova proposição, NWCTI, assim como já havia ocorrido nas verificações para a Cidade Universitária. Em termos de acertos preditivos, os resultados foram dos menos significativos de todos os modelos considerados, com apenas $35 \%$ e $30 \%$, respectivamente para WCTI e NWCTI.

O ITS apresentou correlações mais significativas: 0,75 para o parâmetro do modelo, 0,65 para a interpretação do índice original, e 0,73 e 0,75 para as calibrações na Cidade Universitária e Bairro da Luz respectivamente. Notam-se resultados muito menos significativos do que os encontrados nas simulações realizadas para a Cidade Universitária $(0,86,0,76$ e 0,86$)$. Observa-se ainda que o correlativo, para o caso do Bairro da Luz, é pequeno com a nova calibração, apresentando acertos preditivos bem abaixo do caso da Cidade Universitária (55\% e $81 \%)$.

Já o PhS apresentou correlação melhor: 0,78 para o parâmetro do modelo, 0,78 para a interpretação do índice original, e 0,74 e 0,78 para as calibrações na Cidade Universitária e Bairro da Luz respectivamente. Interessante observar que os resultados correlativos para a interpretação do índice foram mais significativos para o caso do índice original $(0,78)$ do que para o índice calibrado na Cidade Universitária $(0,74)$. É também interessante observar que a nova calibração na Cidade Universitária eleva a correlação apenas para o patamar original $(0,78)$, ainda que os acertos preditivos sejam ligeiramente maiores $(55 \%$ contra 52\%), mas claramente inferiores aos resultados finais encontrados na Cidade Universitária (81\%).
Por fim, assim como no estudo específico da Cidade Universitária, o índice de estresse térmico que apresentou melhor desempenho foi o HL: 0,86 para o parâmetro do modelo, 0,76 para a interpretação do índice original, e 0,85 e 0,86 para as calibrações na Cidade Universitária e Bairro da Luz respectivamente. Observa-se que os valores do índice apresentaram correlação bem mais significativa que os demais. No estudo específico do Bairro da Luz, deve-se destacar que esse índice apresentou os melhores resultados com relação a todos os modelos verificados, inclusive ligeiramente melhores do que o modelo de temperatura equivalente percebida, especificamente proposto a partir da base empírica da Cidade Universitária. Contudo, ainda assim, observa-se que a porcentagem de acertos preditivos no Bairro da Luz (68\%) é menos significativa do que no estudo anterior $(83 \%)$.

\section{Modelos de sensação térmica}

Para a consideração dos resultados dos índices baseados em modelos de sensação térmica, comumente referidos como índices de conforto térmico, três subgrupos foram estabelecidos, com base no critério interpretativo de seus índices. Dessa forma, têm-se:

(a) índices de sensação térmica baseados em parâmetros fisiológicos;

(b) índices de sensação térmica baseados em parâmetros qualitativos; e

(c) índices de sensação térmica baseados em analogia.

\section{Índices de sensação térmica baseados em parâmetros fisiológicos}

Os índices ECI, STE, PSI e S do modelo COMFA, baseados em modelos analíticos, são aqui considerados. Na Tabela 9 constam os resultados para os referidos índices.

\begin{tabular}{|c|c|c|c|c|c|c|c|c|c|c|c|c|c|}
\hline \multirow{2}{*}{\multicolumn{2}{|c|}{$\begin{array}{c}\text { Base empírica } \\
\text { Calibração }\end{array}$}} & \multicolumn{5}{|c|}{ Cidade Universitária } & \multicolumn{7}{|c|}{ Bairro da Luz } \\
\hline & & \multirow[b]{2}{*}{ Cpm } & \multicolumn{2}{|c|}{ Io } & \multicolumn{2}{|c|}{ Ic,c } & \multirow[b]{2}{*}{ Cpm } & \multicolumn{2}{|c|}{ Io } & \multicolumn{2}{|c|}{ Ic,c } & \multicolumn{2}{|c|}{ Ic,b } \\
\hline Modelo & Índices & & Cfi & $\%$ ap & Cfi & $\%$ ap & & Cfi & $\%$ ap & Cfi & $\%$ ap & Cfi & $\%$ ap \\
\hline COMFA & $\mathbf{S}$ & 0,87 & 0,63 & $58 \%$ & 0,84 & $81 \%$ & 0,84 & 0,67 & $59 \%$ & 0,69 & $43 \%$ & 0,76 & $52 \%$ \\
\hline MENEX & ECI & 0,73 & 0,74 & $36 \%$ & 0,70 & $61 \%$ & 0,67 & 0,74 & $50 \%$ & 0,74 & $39 \%$ & 0,76 & $53 \%$ \\
\hline De Freitas & PSI & 0,87 & 0,82 & $61 \%$ & 0,85 & $74 \%$ & 0,81 & 0,79 & $27 \%$ & 0,78 & $31 \%$ & 0,79 & $41 \%$ \\
\hline “ & STE & 0,78 & 0,71 & $54 \%$ & 0,80 & $74 \%$ & 0,68 & 0,67 & $27 \%$ & 0,73 & $50 \%$ & 0,77 & $41 \%$ \\
\hline
\end{tabular}

Tabela 9 - Resultados para índices de sensação térmica baseados em parâmetros fisiológicos 


\begin{tabular}{|c|c|c|c|c|c|c|c|c|c|c|c|c|c|}
\hline \multirow{2}{*}{\multicolumn{2}{|c|}{$\begin{array}{c}\text { Base empírica } \\
\text { Calibração }\end{array}$}} & \multicolumn{5}{|c|}{ Cidade Universitária } & \multicolumn{7}{|c|}{ Bairro da Luz } \\
\hline & & \multirow[b]{2}{*}{ Cpm } & \multicolumn{2}{|c|}{ Io } & \multicolumn{2}{|c|}{ Ic,c } & \multirow[b]{2}{*}{ Cpm } & \multicolumn{2}{|c|}{ Io } & \multicolumn{2}{|c|}{ Ic,c } & \multicolumn{2}{|c|}{ Ic,b } \\
\hline Modelo & Índices & & Cfi & $\%$ ap & Cfi & $\%$ ap & & Cfi & $\%$ ap & Cfi & \%ap & Cfi & $\%$ ap \\
\hline KMM & PMV & 0,78 & 0,72 & $56 \%$ & 0,76 & $69 \%$ & 0,65 & 0,64 & $39 \%$ & 0,75 & $61 \%$ & 0,78 & $57 \%$ \\
\hline Tne & Tne & 0,87 & 0,74 & $31 \%$ & 0,87 & $81 \%$ & 0,71 & 0,61 & $36 \%$ & 0,66 & $48 \%$ & 0,70 & $57 \%$ \\
\hline TS & TS & 0,86 & 0,83 & $69 \%$ & 0,86 & $80 \%$ & 0,63 & 0,61 & $32 \%$ & 0,68 & $41 \%$ & 0,72 & $48 \%$ \\
\hline ASV & ASV & 0,84 & 0,74 & $61 \%$ & 0,81 & $79 \%$ & 0,76 & 0,67 & $30 \%$ & 0,76 & $34 \%$ & 0,78 & $34 \%$ \\
\hline
\end{tabular}

Tabela 10 - Resultados para índices de sensação térmica baseados em parâmetros

O ECI e o STE apresentaram as correlações mais baixas do grupo de índices de sensação térmica baseados em parâmetros fisiológicos: respectivamente 0,67 e 0,68 para o parâmetro do modelo, 0,74 e 0,67 para a interpretação dos índices originais, 0,74 e 0,73 para os índices calibrados na Cidade Universitária, e 0,76 e 0,77 para os índices calibrados no Bairro da Luz. Contudo, em termos de acertos preditivos, deve-se mencionar que o ECI apresentou resultado final de $53 \%$ contra $41 \%$ do STE, que, apesar do aumento da correlação, apresentou queda na porcentagem de acertos preditivos. Ressalta-se aqui o critério adotado para as calibrações, em que se maximiza a correlação, e não os acertos preditivos, uma vez que correlações mais altas indicam maior possibilidade de acertos em outras situações.

O S e o PSI apresentaram as correlações mais significativas do grupo: respectivamente $0,84 \mathrm{e}$ 0,81 para o parâmetro do modelo, 0,67 e 0,79 para a interpretação dos índices originais, 0,68 e 0,78 para os índices calibrados na Cidade Universitária, e 0,76 e 0,79 para os índices calibrados no Bairro da Luz. Contudo, as porcentagens de acertos preditivos desses índices foram distintas: 59\%, $42 \%$ e $52 \%$ para S, contra apenas $27 \%, 31 \%$ e $41 \%$ do PSI. Assim, no grupo de índices de sensação térmica baseados em parâmetros fisiológicos, o índice $\mathrm{S}$, do modelo Comfa, foi o que apresentou os resultados mais significativos, ainda que, assim como se observou nos índices de estresse térmico, as correlações tenham sido mais baixas do que as verificadas nos estudos na Cidade Universitária, assim como a porcentagem de acertos preditivos, $52 \%$ contra $81 \%$, tenha sido também bem menos significativa.

\section{Índices de sensação térmica baseados em parâmetros qualitativos}

$\mathrm{O}$ índice PMV, baseado no modelo analítico KMM, e os índices empíricos Tne, TS e ASV são aqui considerados. A Tabela 10 traz os resultados desses índices.

Os índices de sensação térmica baseados em parâmetros qualitativos apresentaram, em conjunto, os resultados menos expressivos do estudo. $\mathrm{O}$ índice TS apresentou correlações de 0,63 para o parâmetro do modelo, 0,61 para a interpretação do índice original, e 0,68 e 0,72 para as calibrações na Cidade Universitária e no Bairro da Luz respectivamente. O índice Tne apresentou correlações de 0,71 para o parâmetro do modelo, 0,61 para a interpretação do índice original, e 0,66 e 0,70 para as calibrações na Cidade Universitária e no Bairro da Luz respectivamente. Esses dois índices haviam apresentado os resultados mais significativos do grupo com o estudo por meio da base empírica da Cidade Universitária, com correlações respectivamente de 0,86 e 0,87 , tanto para o parâmetro do modelo quanto para as faixas interpretativas dos índices calibrados. $\mathrm{O}$ porcentual de acertos preditivos também foi alto: respectivamente $80 \%$ e $81 \%$. Observam-se, no estudo com base empírica no Bairro da Luz, acertos preditivos de apenas $48 \%$ e $57 \%$ respectivamente.

Já os índices PMV e ASV, ainda que não tivessem apresentado resultados tão significativos no estudo na Cidade Universitária, apresentaram correlações mais significativas do grupo: respectivamente 0,65 e 0,76 para o parâmetro do modelo, 0,64 e 0,67 para a interpretação dos índices originais, 0,75 e 0,75 para os índices calibrados na Cidade Universitária, e 0,78 e 0,78 para os índices calibrados no Bairro da Luz. Observa-se que o PMV havia fornecido resultados correlativos mais significativos no estudo na Cidade Universitária, enquanto as correlações para o estudo no Bairro da Luz foram maiores para o índice ASV. Contudo, deve-se atentar para o fato de que, em termos de acertos preditivos, o ASV apresentou resultado final de apenas $34 \%$, um dos resultados mais baixos de todos os índices estudados, contra $57 \%$ do PMV. Nesse sentido, a perda preditiva do PMV 
foi relativamente pequena, de $69 \%$ na Cidade Universitária para $57 \%$ no Bairro da Luz, enquanto a perda do ASV foi muito significativa, de $79 \%$ para $34 \%$. Observa-se, pelos resultados da calibração desse índice, que os limites da faixa interpretativa de neutralidade, para proporcionar maiores correlações, acabaram ficando deveras restritos, levando a um baixo percentual de acertos preditivos.

\section{Índices de sensação térmica baseados em analogia}

São aqui considerados três índices de modelos analíticos (SET*, PET e STI) e quatro índices de modelos empíricos (ET*, CET*, OT, EOT* e TEP), cujos resultados podem ser observados na Tabela 10.

Com relação aos índices de modelos analíticos, o índice SET* apresentou os resultados menos significativos, com correlações de 0,70 para o parâmetro do modelo, 0,66 para a interpretação do índice original, e 0,68 e 0,69 para as calibrações na Cidade Universitária e no Bairro da Luz respectivamente. Por outro lado, entre os índices de modelos analíticos, o resultado final de acertos preditivos foi o mais alto, com 59\%. O índice PET apresentou correlações de 0,75 para o parâmetro do modelo, 0,75 para a interpretação do índice original, e 0,73 e 0,78 para as calibrações na Cidade Universitária e no Bairro da Luz respectivamente. A porcentagem de acertos preditivos foi de $52 \%$, valor abaixo do índice
SET*, mas bem mais significativo que do índice STI. Este índice apresentou apenas 39\% de acertos preditivos, mas apresentou as correlações mais altas dos índices de modelos analíticos: 0,82 para o parâmetro do modelo, 0,80 para a interpretação do índice original, e 0,77 e 0,78 para as calibrações na Cidade Universitária e no Bairro da Luz respectivamente. Conforme também já se verificou para outros índices, os resultados desse subgrupo para a calibração com base nos dados empíricos do Bairro da Luz apresentaram aumentos correlativos significativamente baixos aos dos estabelecidos com base nos da Cidade Universitária.

Com relação aos índices de modelos empíricos, baseados em temperatura efetiva e/ou operativa, os índices ET*, OT e EOT* apresentaram resultados correlativos semelhantes, inclusive sendo o único subgrupo a manter, de uma forma geral, a mesma ordem de grandeza dos resultados correlativos encontrados na verificação na Cidade Universitária. Para a base empírica do Bairro da Luz, esses índices apresentaram resultados correlativos, respectivamente, de $0,73,0,66$ e 0,61 para o parâmetro do modelo; 0,66, 0,62 e 0,64 para a interpretação dos índices originais; 0,72, 0,70 e 0,74 para os índices calibrados na Cidade Universitária; e 0,74, 0,72 e 0,76 para os índices calibrados no Bairro da Luz. Com relação aos resultados finais de acertos preditivos, têm-se respectivamente: $55 \%$, $55 \%$ e $48 \%$ contra $61 \%$, $64 \%$ e $65 \%$ no estudo feito com base na Cidade Universitária.

\begin{tabular}{|c|c|c|c|c|c|c|c|c|c|c|c|c|c|}
\hline \multirow{2}{*}{\multicolumn{2}{|c|}{$\begin{array}{c}\text { Base empírica } \\
\text { Calibração }\end{array}$}} & \multicolumn{5}{|c|}{ Cidade Universitária } & \multicolumn{7}{|c|}{ Bairro da Luz } \\
\hline & & \multirow[b]{2}{*}{ Cpm } & \multicolumn{2}{|c|}{ Io } & \multicolumn{2}{|c|}{ Ic,c } & \multirow[b]{2}{*}{ Cpm } & \multicolumn{2}{|c|}{ Io } & \multicolumn{2}{|c|}{ Ic,c } & \multicolumn{2}{|c|}{ Ic,b } \\
\hline Modelo & Índices & & Cfi & $\%$ ap & Cfi & $\%$ ap & & Cfi & $\%$ ap & Cfi & $\%$ ap & Cfi & $\%$ ap \\
\hline ET & ET* & 0,69 & 0,58 & $40 \%$ & 0,64 & $61 \%$ & 0,73 & 0,66 & $23 \%$ & 0,72 & $48 \%$ & 0,74 & $55 \%$ \\
\hline ET & CET* $^{*}$ & 0,88 & 0,79 & $55 \%$ & 0,84 & $81 \%$ & 0,85 & 0,81 & $41 \%$ & 0,82 & $61 \%$ & 0,83 & $66 \%$ \\
\hline OT & OT & 0,71 & 0,63 & $39 \%$ & 0,71 & $64 \%$ & 0,66 & 0,62 & $34 \%$ & 0,70 & $40 \%$ & 0,72 & $55 \%$ \\
\hline $\mathbf{E T}+\mathbf{O T}$ & EOT* & 0,67 & 0,66 & $36 \%$ & 0,73 & $65 \%$ & 0,61 & 0,64 & $45 \%$ & 0,74 & $52 \%$ & 0,76 & $48 \%$ \\
\hline Gagge & SET* $*$ & 0,82 & 0,79 & $19 \%$ & 0,81 & $65 \%$ & 0,70 & 0,66 & $11 \%$ & 0,68 & $52 \%$ & 0,69 & $59 \%$ \\
\hline $\begin{array}{l}\text { MENE } \\
X \\
\end{array}$ & STI & 0,86 & 0,77 & $52 \%$ & 0,81 & $78 \%$ & 0,82 & 0,80 & $14 \%$ & 0,77 & $23 \%$ & 0,78 & $39 \%$ \\
\hline MEMI & PET & 0,82 & 0,78 & $35 \%$ & 0,85 & $79 \%$ & 0,75 & 0,75 & $32 \%$ & 0,73 & $55 \%$ & 0,78 & $52 \%$ \\
\hline TEP & TEP & 0,93 & - & - & 0,93 & $96 \%$ & 0,85 & - & - & 0,85 & $59 \%$ & 0,86 & $66 \%$ \\
\hline
\end{tabular}

Tabela 11 - Resultados para índices de sensação térmica baseados em analogia 
$\mathrm{O}$ índice $\mathrm{CET}^{*}$ foi o que apresentou resultados bem mais significativos, em grande parte provavelmente devido às altas correlações encontradas entre as respostas subjetivas e os valores de temperatura de globo. As correlações do índice foram de 0,85 para o parâmetro do modelo, 0,81 para a interpretação do índice original, 0,82 para o índice calibrado na Cidade Universitária, e 0,83 para o índice calibrado no Bairro da Luz, com resultado final de acertos preditivos de $66 \%$, resultado geral muito satisfatório, que fica atrás apenas, em termos de todos os índices estudados, do HL do modelo analítico MENEX e do TEP.

Com relação ao índice TEP, que recebe aqui particular atenção, uma vez que foi proposto com base nos dados empíricos coletados na Cidade Universitária, ele apresentou, comparativamente aos outros índices, resultados bastante significativos. O TEP apresenta correlações de 0,85 para o parâmetro do modelo, 0,85 para a interpretação do índice original, que foi estabelecido na Cidade Universitária, e 0,86 para o índice calibrado no Bairro da Luz. O resultado final de acertos preditivos é de $66 \%$, valor igual ao do $\mathrm{CET}^{*}$ e superado apenas pelo HL do modelo MENEX. Por outro lado, assim como aconteceu com a quase totalidade dos índices verificados neste estudo, as correlações são menos significativas do que na Cidade Universitária $(0,93$ para o parâmetro do modelo e 0,93 para as faixas interpretativas do índice), e os acertos preditivos ainda menos significativos, uma vez que originalmente, na Cidade Universitária, tinha-se um valor de $96 \%$.

\section{Considerações finais}

Como consideração geral, pode-se afirmar que as situações microclimáticas levantadas no Bairro da Luz e os respectivos resultados em termos de respostas de percepção de sensação térmica apresentam-se menos previsíveis do que os verificados na Cidade Universitária. Esse fato deve-se à heterogeneidade das situações e populações levantadas e ao caráter dos levantamentos, uma vez que foram realizados em situações urbanas reais, menos controláveis do que os levantamentos na Cidade Universitária, de caráter laboratorial.

Nessa perspectiva, é compreensível o fato de que todos os índices tenham apresentado resultados correlativos menos significativos, mesmo com calibrações realizadas com a própria base empírica do Bairro da Luz. É interessante observar também que a diferença é ainda mais acentuada em termos dos acertos preditivos, em que as porcentagens foram muito mais baixas do que as encontradas na Cidade Universitária, apontando que as calibrações realizadas não conseguem melhorar as predições da amostra em específico, conforme conseguiram no caso dos levantamentos laboratoriais, de caráter mais controlável.

Por fim, ressaltam-se os resultados gerais das simulações e calibrações realizadas, apontando para os índices que obtiveram melhores resultados, a fim de dar prosseguimento aos estudos da base empírica do Bairro da Luz. A Tabela 12 apresenta os 5 índices, do conjunto de 29 estudados, que apresentaram os resultados mais significativos e, ainda, a média geral do referido grupo de 29 índices.

\begin{tabular}{|c|c|c|c|c|c|c|c|c|c|c|c|c|c|}
\hline \multirow{2}{*}{\multicolumn{2}{|c|}{$\begin{array}{c}\text { Base empírica } \\
\text { Calibração }\end{array}$}} & \multicolumn{5}{|c|}{ Cidade Universitária } & \multicolumn{7}{|c|}{ Bairro da Luz } \\
\hline & & \multirow[b]{2}{*}{ Cpm } & \multicolumn{2}{|c|}{ Io } & \multicolumn{2}{|c|}{ Ic,c } & \multirow[b]{2}{*}{ Cpm } & \multicolumn{2}{|c|}{ Io } & \multicolumn{2}{|c|}{ Ic,c } & \multicolumn{2}{|c|}{ Ic,b } \\
\hline Modelo & Índices & & Cfii & $\%$ ap & Cfi & $\%$ ap & & Cfi & $\%$ ap & Cfi & $\%$ ap & Cfi & $\%$ ap \\
\hline ET & CET* & 0,88 & 0,79 & $55 \%$ & 0,84 & $81 \%$ & 0,85 & 0,81 & $41 \%$ & 0,82 & $61 \%$ & 0,83 & $66 \%$ \\
\hline Vogt & Swreq & 0,86 & - & - & 0,85 & $76 \%$ & 0,82 & - & - & 0,81 & $59 \%$ & 0,83 & $57 \%$ \\
\hline Sevilha & Swreq' & 0,88 & 0,84 & $72 \%$ & 0,88 & $78 \%$ & 0,81 & 0,60 & $45 \%$ & 0,82 & $57 \%$ & 0,85 & $64 \%$ \\
\hline MENEX & HL & 0,88 & 0,83 & $63 \%$ & 0,87 & $83 \%$ & 0,86 & 0,76 & $41 \%$ & 0,85 & $64 \%$ & 0,86 & $68 \%$ \\
\hline TEP & TEP & 0,93 & - & - & 0,93 & $96 \%$ & 0,85 & - & - & 0,85 & $59 \%$ & 0,86 & $66 \%$ \\
\hline \multicolumn{2}{|c|}{ Média (29 índices) } & 0,81 & 0,74 & $49 \%$ & 0,81 & $75 \%$ & 0,74 & 0,67 & $33 \%$ & 0,72 & $46 \%$ & 0,74 & $51 \%$ \\
\hline
\end{tabular}

Tabela 12 - Grupos de resultados mais significativos e médias gerais 
Com relação aos modelos de esforço fisiológico, os índices de estresse térmico Swreq, de Vogt, e Swreq', de Sevilha, apresentaram resultados significativos, ainda que tenham sido originalmente desenvolvidos apenas para a predição de situações de calor. $O$ modelo de Sevilha, em verdade, é baseado no modelo de Vogt, com pequenas considerações distintas, fato que explica os resultados similares, sendo respectivamente para o de Vogt e de Sevilha 0,82 e 0,81 para o parâmetro do modelo, 0,81 e 0,82 para os índices calibrados na Cidade Universitária, e 0,83 e 0,85 para os índices calibrados no Bairro da Luz, com $57 \%$ e $64 \%$ de acertos preditivos.

Com relação aos modelos de esforço fisiológico, os índices de estresse térmico Swreq, de Vogt, e Swreq', de Sevilha, apresentaram resultados significativos, ainda que tenham sido originalmente desenvolvidos apenas para a predição de situações de calor. O modelo de Sevilha, em verdade, é baseado no modelo de Vogt, com pequenas considerações distintas, fato que explica os resultados similares, sendo respectivamente para o de Vogt e de Sevilha 0,82 e 0,81 para o parâmetro do modelo, 0,81 e 0,82 para os índices calibrados na Cidade Universitária, e 0,83 e 0,85 para os índices calibrados no Bairro da Luz, com $57 \%$ e $64 \%$ de acertos preditivos.

O índice CET*, baseado no modelo empírico de temperatura efetiva, apresentou resultados ainda mais significativos, que, conforme já apontado, se devem em parte à alta correlação dos resultados das respostas subjetivas e dos valores de temperatura de globo. Assim, têm-se 0,85 para o parâmetro do modelo, 0,81 para a interpretação do índice original, 0,82 e 0,83 para o índice calibrado, respectivamente, com base na Cidade Universitária e no Bairro da Luz, com resultado final de acertos preditivos de $66 \%$. Os resultados encontrados para esse modelo, assim como as significativas correlações com as temperaturas de globo levam à possibilidade de explorações dessa variável para a predição das sensações térmicas.

$\mathrm{O}$ índice HL, calculado com base no modelo analítico de balanço térmico MENEX, foi o que apresentou resultados mais significativos de todos os índices: 0,86 para o parâmetro do modelo, 0,76 para a interpretação do índice original, e 0,85 e 0,86 para as calibrações com base na Cidade Universitária e no Bairro da Luz respectivamente. Apresentou ainda a maior porcentagem de acertos preditivos, com resultado final de $68 \%$. Assim, para explorações teóricas acerca da base empírica em estudo, será utilizado o modelo MENEX e o índice HL.
Finalmente, o índice TEP, proposto especificamente com base nos dados empíricos da Cidade Universitária, apresentou resultados muito significativos, abaixo apenas dos do índice HL, mas ainda muito próximos aos dele: 0,85 para o parâmetro do modelo, e 0,85 e 0,86 para as calibrações com base na Cidade Universitária e no Bairro da Luz. A porcentagem de acertos preditivos foi de $66 \%$, atrás também apenas do índice HL. Ainda que tenha apresentado resultados ligeiramente inferiores ao do HL, o índice TEP será considerado em trabalhos futuros de pesquisa, uma vez que apresenta modelagem muito mais simples e objetiva do que a proposta pelo modelo MENEX, do índice HL. Assim, serão considerados não apenas os resultados do modelo TEP, mas principalmente os métodos de regressão e considerações teóricas envolvidos em sua proposição.

Em suma, os índices CET*, TEP e HL, que apresentaram os resultados mais significativos para a predição da percepção de sensações térmicas, permitem vislumbrar aplicações em trabalhos futuros, respectivamente com relação a:

(a) possibilidades de verificação de modelos preditivos simplificados, com base em temperatura de globo, em situações onde se realizem levantamentos in loco;

(b) verificação de modelagens empíricas baseadas em regressões estatísticas de múltiplas variáveis, permitindo modelos preditivos simplificados, sem necessidade de levantamentos posteriores in loco; e

(c) verificações e extrapolações teóricas de bases empíricas existentes, ou ainda a serem estabelecidas.

\section{Referências}

\section{AMERICAN SOCIETY OF HEATING, REFRIGERATING AND AIR CONDITIONING ENGINEERS. ASHRAE 55: thermal} environmental conditions for human occupancy. Atlanta: ASHRAE, 2004.

\author{
AMERICAN SOCIETY OF HEATING, \\ REFRIGERATING AND AIR CONDITIONING \\ ENGINEERS. Thermal Environmental \\ Conditions for Human Occupancy. Atlanta, \\ ASHRAE, 1967.
}

\author{
AMERICAN SOCIETY OF HEATING, \\ REFRIGERATING AND AIR CONDITIONING \\ ENGINEERS. Handbook of Fundamentals. \\ Atlanta: ASHRAE, 2005.
}


AMERICAN SOCIETY OF HEATING, REFRIGERATING AND AIR CONDITIONING ENGINEERS. ASHRAE 55. Thermal

Environmental Conditions for Human Occupancy. Atlanta: ASHRAE, 1992.

AROZTEGUI, M. Cuantificación del Impacto de las Sombras de los Edificios. In: III ENCONTRO NACIONAL E I ENCONTRO LATINOAMERICANO SOBRE CONFORTO NO AMBIENTE CONSTRUÍDO, 1995, Gramado. Anais... ANTAC, 1995.

BELDING, H.; HATCH, T. Index for Evaluating Heat Stress in Terms of Resulting Physiological Strain. Heating, Piping, Air Conditioning, v. 27, p. 129-142, 1955.

BLAZEJCZYK, K. Menex 2002. 2002.

Disponível em:

〈http://www.igipz.pan.pl/klimat/blaz/menex.htm>. 2002. Acesso em: 24 abr. 2004

BLAZEJCZYK, K. Climatological-andphysiological model of the human heat balance outdoor and its applications in bioclimatological studies in different scales. Zeszyty IGiPZ PAN, 28 , p.27-58, 1996.

BLUESTEIN, M.; OSCZEVSKI, R. Wind Chill and the Development of Frostbite in the Face. In: Conference on Biometeorology and Aerobiology, 15., Kansas, 2002. Proceedings... Kansas, 2002. p. $168-171$.

BRASIL. MINISTÉRIO DO TRABALHO. NR15: atividades e operações insalubres, anexo 3 , limites e tolerância para exposição ao calor. Brasília: Ministério do Trabalho, 1978.

BROWN, R. D.; GILLESPIE, T. J. Microclimatic landscape design: creating thermal comfort and energy efficiency. New York: John Wiley \& Sons, 1995.

DEAR, R. de; PICKUP, J. An Outdoor Thermal Comfort Index: applications. In: INTERNATIONAL CONGRESS OF BIOMETEOROLOGY, 15., 1999, Sydney. Proceedings... Geneve: WMO, 20000. p.285-290.

DEAR, R.; BRAGER, G.; COOPER, L. Developing an Adaptative Model of Thermal Comfort and Preference. Sydney: ASHRAE, 1997.

DOMINGUEZ, A. et al. Control Climático en Espacios Abiertos. Sevilla: Universidad de Sevilla, 1992.
FANGER, P. O. Thermal Comfort: analysis and application in environment engineering. New York: McGraw Hill, 1972.

FREITAS, C. R. de. Recreation Climate Assessment. International Journal of Climatology, v. 10, p. 89-103, 1997.

GAGGE, A. et al. A Standard Predictive Index of Human Response to the Thermal Environment. ASHRAE Trans, v. 92, p. 709-731, 1986.

GAGGE, A. P.; STOLWIJK J. A. J.; HARDY, J. D. Comfort and Thermal Sensations and Associated Physiological Responses at Various Ambient Temperatures. Environmental Research, v. 1, n. 1, p. 1-20, 1967.

GIVONI, Baruch. Man, Climate and Architecture. New York: John Wiley \& Sons, 1969.

GIVONI, Baruch; NOGUCHI, Mikiko. Issues in Outdoor Comfort Research. In: PASSIVE AND LOW ENERGY ARCHITECTURE, 17., 2000, Cambridge. Proceedings... London: James \& James, 2002. p. 562-565.

HÖPPE, P. The Physiological Equivalent Temperature: a universal index for the assessment of the thermal environment. International Journal of Biometeorology, v. 43, n. 2, p. 71-75, 1999.

HOUGHTEN, F. C.; YAGLOU, C. P.

Determining Lines of Equal Comfort. ASHVE Transactions, v. 29, p.163-169, 1923.

HUMPHREYS, M. Field Studies of Thermal Comfort Compared and Applied. BRE Current Paper, London, v. 75/76, 1975.

HUMPHREYS, M. Outdoor temperatures and comfort indoors. Building Research and Practice, v. 6, p. 92-105, 1978.

INTERNATIONAL ORGANIZATION FOR STANDARDIZATION. ISO 7726: ergonomics: instruments for measuring physical quantities. Genève: ISO, 1998.

\section{INTERNATIONAL ORGANIZATION FOR} STANDARDIZATION. ISO 7730: ergonomics of the thermal environment: analytical determination and interpretation of thermal comfort using calculation of the PMV and PPD indices and local thermal comfort criteria. Genève: ISO, 2005. 
INTERNATIONAL ORGANIZATION FOR STANDARDIZATION. ISO 9920: ergonomics of the thermal environment: estimation of the thermal insulation and evaporative resistance of a clothing ensemble. Genève: ISO, 1995.

\section{INTERNATIONAL ORGANIZATION FOR}

STANDARDIZATION. ISO 10551: ergonomics of the thermal environment: assessment of the influence of the thermal environment using subjective judgement scales. Genève: ISO, 1995.

INTERNATIONAL ORGANIZATION FOR STANDARDIZATION. ISO 8996: ergonomics: metabolic heat production. Genève: ISO, 1990.

\section{INTERNATIONAL ORGANIZATION FOR} STANDARDIZATION. ISO 7933: hot environments: analytical determination and interpretation of thermal stress using calculation of required sweat rate. Genève: ISO, 1989.

\section{INTERNATIONAL ORGANIZATION FOR} STANDARDIZATION. ISO 7243. Hot environments: estimation of the heat stress on working man, based on the WBGT-index (wet bulb globe temperature). Genève: ISO, 1989.

\section{JENDRITZKY, Gerd. Klimatologische}

Probleme: ein einfaches Verfahren zur Vorhersage der Wärmebelastung, in Zeitschrift für angewandte Bäder und Klimaheilkunde. Freiburg, 1979.

JENDRITZKY, Gerd. Selected Questions of Topical Interest in Human Bioclimatology. International Journal of Biometeorology, v. 35, n. 3, p. 139-150, 1991.

MASTERTON, J.; RICHARDSON, F. Humidex: a method of quantifying human discomfort. In: Environment Canada: CLI 1-79. Ontario, Downsview: Atmospheric Environment Service, 1979.

\section{MONTEIRO, L. M. Modelos preditivos de} conforto térmico: quantificação de relações entre variáveis microclimáticas e de sensação térmica para avaliação e projeto de espaços abertos. 2008. 378 f. Tese (Doutorado em Arquitetura e Urbanismo) - Faculdade de Arquitetura e Urbanismo, Universidade de São Paulo, São Paulo, 2008.
MONTEIRO, L.; ALUCCI, M. Procedimentos para quantificação de variáveis para análise termofisiológica. In: ENCONTRO NACIONAL DE CONFORTO NO AMBIENTE CONSTRUÍDO, 8.; ENCONTRO LATINO-AMERICANO DE CONFORTO NO AMBIENTE CONSTRUÍDO, 6., Maceió, 2005. Anais... Maceió: ANTAC, 2005.

MONTEIRO, L.; ALUCCI, M. Questões Teóricas de Conforto Térmico em Espaços Abertos: consideração histórica, discussão do estado da arte e proposição de classificação de modelos.

Ambiente Construído, v. 7, n. 3, p. 43-58, jul./set. 2007.

NIKOLOPOULOU, Marialena (Org). Designing Open Spaces in the Urban Environment: a Bioclimatic Approach. Atenas: CRES, 2004.

SIPLE, P.; PASSEL C. Measurements of Dry Atmospheric Cooling in Subfreezing Temperatures. Proceedings of the American Philosophical Society, v. 89, n. 1, p. 177-199, 1945.

SZOKOLAY, Steven V. Use of the new effective temperature: $\mathrm{ET}^{*}$ in practice. . In: PASSIVE AND LOW ENERGY ARCHITECTURE, 18, 2001, Florianópolis. Proceedings... 2001.

VERNON, H. M.; WARNER, C. G. The influence of the humidity of the air on capacity for work at high temperatures. J. Hyg., v.32, p.431462, 1932.

VOGT et al. A thermal environment in physiologically significant terms. Archives for Meteorology, Geophysics, and Bioclimatology, v. 29, p. 313-326, 1981.

WINSLOW, C. E. A.; HERRINGTON, L. P.; GAGGE, A. P. Relations between atmospheric conditions, physiological reactions and sensations of pleasantness. American Journal of Hygiene, v. 26, n. 1, p. 103-115, 1937.

YAGLOU, C.; MINARD, D. Control of Heat Casualties at Military Training Centers. Archives of Industrial Health, n. 16, p. 302-16, 1957.

\section{Agradecimentos}

Os autores agradecem à Fundação de Amparo a Pesquisa do Estado de São Paulo (FAPESP), pelo apoio financeiro, e ao Conselho Nacional de Desenvolvimento Científico e Tecnológico (CNPq), pelos auxílios à pesquisa. 